\title{
El escape room virtual: herramienta docente universitaria para el desarrollo de competencias transversales y para la retención del conocimiento
}

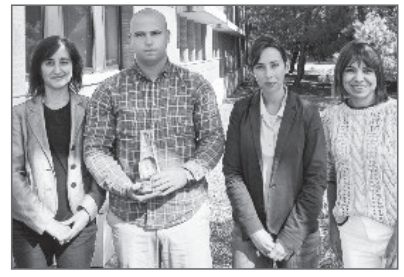

\author{
Alejandro Salvador-Gómez \\ Personal docente e investigador de la Universitat Jaume I \\ de Castellón de la Plana (España) \\ alsalvad@uji.es | https://orcid.org/0000-0003-3115-7185
}

Ana Belén Escrig-Tena

Catedrática de la Universitat Jaume I de Castellón de la Plana (España) escrigt@uji.es | https://orcid.org/0000-0001-8471-2336

Inmaculada Beltrán-Martín

Profesora titular de la Universitat Jaume I de Castellón de la Plana (España) ibeltran@uji.es | https://orcid.org/0000-0002-0425-4070

Beatriz García-Juan

Profesora ayudante doctora de la Universitat Jaume I de Castellón de la Plana (España) bjuan@uji.es | https://orcid.org/0000-0002-8785-1101

Este trabajo ha obtenido el 1. er Premio Estudios Financieros 2021 en la modalidad de Educación y Nuevas Tecnologías.

El jurado ha estado compuesto por: don Manuel Area Moreira, don Julio Barroso Osuna, doña Ana GarcíaValcárcel Muñoz-Repiso, don José Hernández Ortega y don Javier de los Ríos Medina.

Los trabajos se presentan con seudónimo y la selección se efectúa garantizando el anonimato de los autores.

\section{Extracto}

El escape room es una actividad de entretenimiento que puede ser aprovechada para fomentar el aprendizaje y las competencias transversales del estudiantado (hombres y mujeres). Las características de este juego son propicias para enganchar al alumnado en la resolución de los retos educativos. Aunque es una herramienta de creciente uso en el ámbito educativo, su aplicación en formato digital en el entorno universitario es relativamente escasa. Este trabajo muestra la experiencia de aplicar un escape room virtual en un grado universitario en España. Los resultados evidencian que el estudiantado experimenta calidad y satisfacción con el juego y sugieren, también, que a través del escape room virtual se pueden lograr objetivos de aprendizaje específicos y desarrollar competencias como la gestión emocional y el trabajo en equipo. Finalmente, discutimos las principales implicaciones y lecciones aprendidas.

Palabras clave: escape room; aprendizaje basado en juegos; teoría del flujo; retención de conocimiento; desarrollo de competencias transversales; juegos virtuales; gamificación.

Fecha de entrada: 04-05-2021 / Fecha de aceptación: 10-09-2021

Cómo citar: Salvador-Gómez, A., Escrig-Tena, A. B., Beltrán-Martín, I. y García-Juan, B. (2022). El escape room virtual: herramienta docente universitaria para el desarrollo de competencias transversales y para la retención del conocimiento. Tecnología, Ciencia y Educación, 21, 7-48. https://doi.org/10.51302/tce.2022.664 


\title{
Virtual escape room: a university teaching tool for developing transversal competencies and knowledge retention
}

\author{
Alejandro Salvador-Gómez \\ Ana Belén Escrig-Tena \\ Inmaculada Beltrán-Martín \\ Beatriz García-Juan
}

\section{Abstract}

The escape room is a game that may be used to improve students' (men and women) learning and foster transversal competencies. The characteristics of this game are suitable to engage students in the solving of the educational challenges. Despite its growing use in educational contexts, there is limited evidence of its application in the university environment, particularly on a digital platform. This paper shows the experience of applying a virtual escape room in a Spanish university degree. Results shown in this study reveal that participants experience a high-quality game and a high level of satisfaction with the game and also indicate that through the virtual escape room, targeted learning goals and transversal competencies such as emotional management and teamwork can be achieved. We conclude by discussing the key implications and the lessons learned.

Keywords: escape room; game-based learning; flow theory; knowledge retention; development of transversal competencies; virtual games; gamification.

Citation: Salvador-Gómez, A., Escrig-Tena, A. B., Beltrán-Martín, I. and García-Juan, B. (2022). Virtual escape room: a university teaching tool for developing transversal competencies and knowledge retention. Tecnología, Ciencia y Educación, 21, 7-48. https://doi.org/10.51302/tce.2022.664 


\section{Sumario}

1. Introducción

2. Bases teóricas

2.1. La teoría del flujo

2.2. Aprendizaje basado en juegos digitales

2.3. El escape room virtual: concepto, características y etapas de diseño

3. Diseño del escape room virtual

3.1. Objetivos generales del proyecto de innovación

3.2. Contexto del proyecto y objetivos específicos

3.3. Desarrollo del hilo argumental

3.4. Determinación de los aspectos generales del juego

3.5. Selección de la aplicación o software

3.6. Selección y creación de los retos

3.7. Construcción de pistas

3.8. Construcción de los elementos de inmersión

3.9. Elaboración de las instrucciones

3.10. Testeo del escape room

4. Evaluación de la experiencia

4.1. Metodología de evaluación

4.2. Resultados obtenidos

5. Lecciones aprendidas

Referencias bibliográficas

Nota: los/las autores/as del artículo agradecen el apoyo recibido por la Universitat Jaume I al proyecto «Herramientas de gamificación y recursos audiovisuales para la docencia en dirección de empresas» dentro de la convocatoria de Ayudas a la Innovación Educativa para el año 2021. Por otra parte, los/las autores/as del artículo declaran que todos los procedimientos llevados a cabo para la elaboración de este estudio de investigación se han realizado de conformidad con las leyes y directrices institucionales pertinentes. Asimismo, los/las autores/as del artículo han obtenido el consentimiento informado (libre y voluntario) por parte de todas las personas intervinientes en este estudio de investigación. 


\section{Introducción}

Uno de los principales retos educativos, en general, pero también en el ámbito de la docencia universitaria, es lograr adaptarse a un perfil de estudiantado con unas características propias tendentes a un uso cotidiano de las nuevas tecnologías, familiarizado con la búsqueda y el consumo de información en diferentes formatos digitales y por una preferencia por recibir el contenido educativo de forma ágil y lúdica (Álvarez-López y SampabloBuezas, 2020; Prensky, 2011). Por otro lado, estos retos se han visto acrecentados por la pandemia producida por la COVID-19, situación que ha supuesto un avance en la digitalización de nuestro entorno y en la demanda de competencias digitales en los futuros profesionales (livari et al., 2020).

Ante esta situación, se hace un llamamiento desde organismos europeos, como Eurydice (European Commission/Education, Audiovisual and Culture Executive Agency [EACEA]/Eurydice, 2020), para que las instituciones de educación superior aprovechen la oportunidad brindada por la crisis sanitaria y transformen sus propuestas de educación hacia espacios y metodologías con un fuerte componente digital. No obstante, estas propuestas digitales deben tener coherencia con las sugerencias que desde el Es-

Se hace un llamamiento desde organismos europeos, como Eurydice, para que las instituciones de educación superior aprovechen la oportunidad brindada por la crisis sanitaria y transformen sus propuestas de educación hacia espacios y metodologías con un fuerte componente digital pacio Europeo de Enseñanza Superior (EEES) se han venido remarcando en años anteriores. En concreto, impulsar la aplicación de metodologías de enseñanza centradas en promover una mayor implicación del alumnado en su aprendizaje. Como se ha evidenciado, en contraposición con metodologías pasivas, como aquellas que se centran en la mera exposición de contenido, las metodologías activas o mixtas promueven resultados de aprendizaje de mayor calidad (GonzálezMarcos et al., 2021).

El presente trabajo tiene como finalidad desarrollar, aplicar y evaluar una herramienta docente universitaria con capacidad de dar respuesta a estos retos, en especial, la conjugación de lo digital con la implicación activa del alumnado en su aprendizaje. Teniendo en cuenta los beneficios que se reportan con la aplicación de metodologías de aprendizaje basado en juegos digitales, como incremento de la motivación, del interés, de la búsqueda de soluciones, etc. (Admiraal et al., 2011), apostamos por la elaboración de 
un escape room virtual. En este juego, un grupo de personas se adentran en un escenario temático virtual $y$, para salir del mismo, deben tratar de resolver los puzles, los enigmas o las misiones que se van presentando en un periodo de tiempo determinado. En consecuencia, el éxito del grupo en el juego recae directamente en competencias tales como la capacidad de cooperación y comunicación grupal, la habilidad en la resolución de problemas, el pensamiento crítico, la gestión emocional ante el estrés y la frustración, etcétera. No es de extrañar, por tanto, que el escape room (tanto virtual como presencial) esté recibiendo una atención creciente como herramienta pedagógica (SemperePla, 2020; Vergne, et al., 2020).

En nuestro caso, el escape room virtual se enmarca en la asignatura Gestión de Calidad y Recursos Humanos del grado de Relaciones Laborales y Recursos Humanos de cuarto curso de la Universitat Jaume I. A través de esta experiencia piloto, buscamos generar un contexto con la herramienta, a través de la cual el alumnado, de forma lúdica y activa, retenga y potencie conocimientos adquiridos previamente en la asignatura a la par que trabaje ciertas competencias transversales consideradas esenciales en la formación del futuro perfil profesional en la gestión de calidad; especialmente, las habilidades cooperativas y la gestión emocional ante situaciones de cierto estrés.

Para diseñar de forma efectiva esta herramienta, en el segundo apartado tomamos en consideración elementos teóricos que nos ofrece la teoría del flujo (Csikszentmihalyi, 1978), los elementos característicos de cualquier herramienta de aprendizaje basada en el juego (Perrota et al., 2013) y, de forma más concreta, las fases y características de diseño generales que es necesario abordar para construir cualquier escape room con finalidad docente (López-Pernas et al., 2019). La lógica es que con el escape room virtual, por sus características intrínsecas propias de los juegos, podríamos lograr la consecución de objetivos de aprendizaje específicos gracias al fomento de experiencias de flujo en el estudiantado, es decir, estados donde los participantes están tan inmersos y concentrados en la tarea, por el reto que les supone y por su atractivo lúdico y de placer emocional, que aprenden y desarrollan competencias por la inercia del propio estado, de modo que, incluso, el tiempo destinado a esta actividad les parece que pasa «volando».

En el apartado tercero presentamos la experiencia docente mostrando en detalle el diseño del escape room virtual aplicado en la asignatura. En el apartado cuarto, analizamos de forma descriptiva, por un lado, los resultados cuantitativos de las valoraciones en las encuestas de los estudiantes participantes, en relación con su experiencia de juego y con el impacto que ha tenido la actividad en su aprendizaje y, por otro, las valoraciones cualitativas que refuerzan los resultados anteriores y nos sugieren las competencias transversales desarrolladas a través del juego. Finalmente, en el apartado cinco, concluimos reflexionando sobre nuestra experiencia y discutiendo los beneficios aportados, las debilidades docentes y las principales lecciones aprendidas. 


\section{Bases teóricas}

\subsection{La teoría del flujo}

El «flujo» puede definirse como un estado de profunda absorción, concentración y compromiso, el cual es experimentado por un individuo cuando este es partícipe de una actividad que le es intrínsecamente agradable, como cuando un atleta o artista está completamente concentrado y comprometido en su actuación o desempeño deportivo (Csikszentmihaalyi, 1990). Los participantes, en este estado, perciben que su desempeño en la actividad se realiza de forma agradable

$\mathrm{El}$ «flujo» puede definirse como un estado de profunda absorción, concentración y compromiso, el cual es experimentado por un individuo cuando este es partícipe de una actividad que le es intrínsecamente agradable y que la actividad es valiosa por sí misma, es decir, que por el mero hecho de realizarla ya supone un beneficio para los individuos, aunque no sean capaces de llegar a la meta de la misma. Como resultado, los participantes rinden al máximo de sus capacidades (Nakamura y Csikszentmihaalyi, 2002).

Uno de los principales aspectos condicionantes para lograr un estado de flujo en los participantes de una actividad, tal y como se muestra en la figura 1, es que exista un equilibrio entre las exigencias de las tareas implicadas y las destrezas del participante. De forma que, si el participante tiene destrezas muy superiores a las exigidas por la actividad, posiblemente derive en un estado de aburrimiento y apatía, y si tales destrezas son muy inferiores a la dificultad de la tarea, puede provocar que el participante entre en un estado de ansiedad y frustración (Csikszentmihaalyi, 1990). Por otro lado, también es imprescindible que existan los menores elementos distractores posibles, de forma que se fomente una plena concentración por parte de sus participantes. Finalmente, la experiencia del participante con la actividad debe ser valiosa por sí misma. Para lograr estos condicionantes, las actividades deberían tratar de poseer algunos aspectos como los que a continuación se detallan:

- Tareas claras y alcanzables. Las tareas deben poseer cierta dificultad, pero a través del esfuerzo del participante se pueden superar. Además, las metas deben ser explícitas, de modo que se determine de forma clara qué es lo que el participante necesita para lograrlas.

- Progreso y retroalimentación inmediata. El participante debería experimentar que las tareas que debe superar son cada vez más difíciles pero que tienen coherencia con la maestría que adquiere en la superación de las tareas previas. Además, debe recibir retroalimentación instantánea cada vez que supere alguna tarea, de forma que, en todo momento, haya una clara información sobre el progreso alcanzado. 
- Autonomía y control de la actividad. Son las acciones de los participantes lo que determinan su progreso y el logro de las metas, por lo que deben experimentar que en todo momento controlan sus acciones.

- Inmersión en la tarea. La actividad debe ser atractiva y placentera, de manera que los participantes pierdan la noción del tiempo e incluso que, con la realización de la misma, se puedan llegar a despreocupar por otras cuestiones de la vida cotidiana.

Figura 1. Modelo del flujo

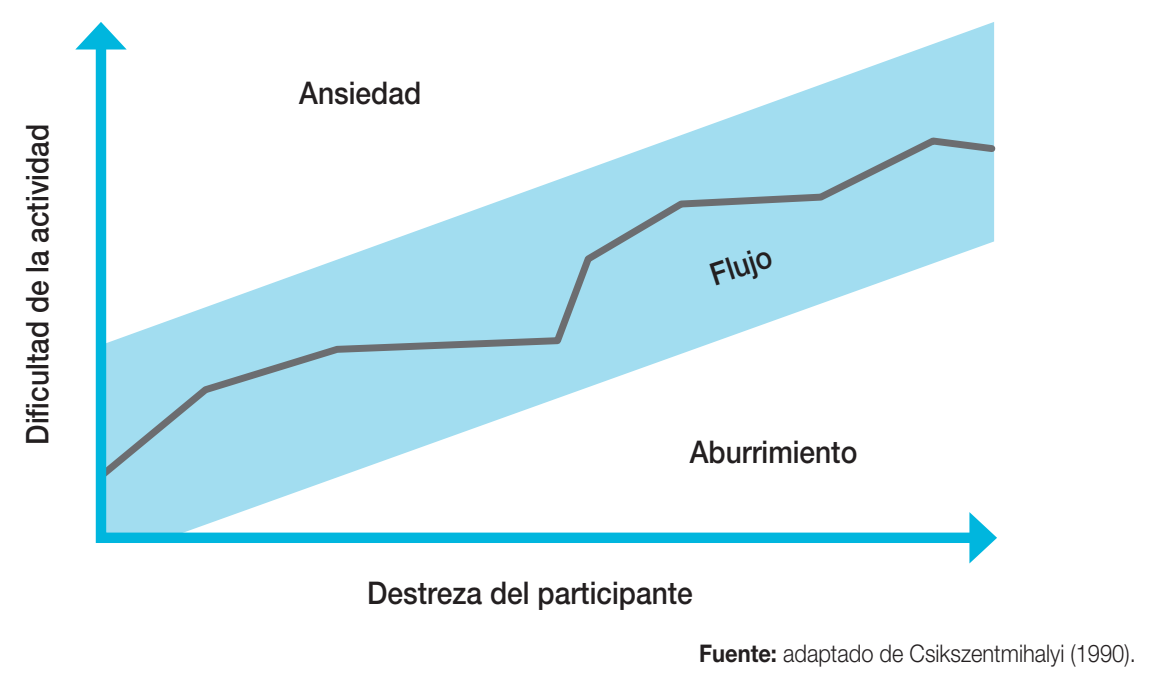

Desde el punto de vista educativo, el estado de flujo puede entenderse como un motor ideal para el fomento del aprendizaje (Csikszentmihalyi, 1990). En otras palabras, lograr mantener al estudiantado en un continuo estado de flujo sería lo más óptimo, ya que, a través de nuevos y continuos desafíos, el estudiante desarrolla habilidades y conocimientos, todo ello bajo sentimientos de satisfacción con las actividades, motivación intrínseca, profunda concentración y ánimo por la participación. Teniendo en mente estas bases teóricas del flujo, en el siguiente epígrafe abordamos la idoneidad de las características del aprendizaje basado en el juego como herramienta educativa capaz de lograr estados de flujo en el estudiante.

\subsection{Aprendizaje basado en juegos digitales}

Es evidente que, hoy en día, la población estudiantil, y también la población en general, muestra determinados comportamientos y actitudes cuando juega a juegos digitales (como el 
interés, la superación continua, la cooperación, la búsqueda activa de información, la búsqueda de soluciones, etc.). Como docentes, nosotros deseamos que nuestros estudiantes muestren estos comportamientos y actitudes en el entorno educativo por su impacto positivo en el aprendizaje y en el desarrollo de competencias (Admiraal et al., 2011). Consecuentemente, el reto es diseñar experiencias de aprendizaje a través de los juegos digitales que evoquen tales actitudes y, en definitiva, que motiven al estudiantado y le impliquen en la asignatura y en sus objetivos. De acuerdo con Garris et al. (2002), un estudiante motivado e inmerso en la asignatura disfruta de lo que está haciendo y se esfuerza prolongadamente en el tiempo. Por tanto, el aprendizaje basado en juegos digitales es una herramienta que, bien diseñada e implementada, reúne las condiciones necesarias para desencadenar experiencias de flujo en los estudiantes (Liu et al., 2011).

Para aplicar esta herramienta, primero, debemos entender qué es un juego digital y sus elementos, y para ello recurrimos a la definición establecida por Kapp (2012), para quien un «juego» es un «sistema en el que los jugadores participan en un reto abstracto, definido por reglas, interactivo y con retroacción, que se traduce en un resultado cuantificable que a menudo provoca una reacción emocional» (p. 7). Si el juego se ejecuta en un entorno virtual (videoconsola, tableta, ordenador, teléfono móvil, etc.), entonces se le denomina «juego virtual» o «videojuego» (Prensky, 2001). Siguiendo a Zichermann y Cunningham (2011), los elementos principales a través de los cuales se desarrolla cualquier juego son:

- Mecánicas. Son las reglas del juego y controlan y modulan el comportamiento de los participantes. Estas reglas deben ser entendidas, aceptadas y respetadas por todos los participantes.

- Dinámicas. Hacen referencia a los patrones o pautas que el participante puede desarrollar dentro del juego en función de lo que le permiten las mecánicas del juego. Por tanto, las dinámicas serán aquellos efectos visibles de las reglas según las acciones y la interacción con otras reglas.

- Estética. Describe cómo es la experiencia del participante con el juego y, por tanto, qué respuestas emocionales le provoca.

El aprendizaje basado en juegos digitales, por tanto, implica utilizar un juego real, en formato virtual, con la finalidad de desarrollar las destrezas y los conocimientos educativos perseguidos. El juego digital es independiente, por lo que tiene un inicio y una finalización, donde hay momentos de éxito para al estudiante que participa, ofreciendo además distintos contenidos educativos en varios escenarios (Kapp, 2012). Es relevante resaltar algunas diferencias con el concepto de «gamificación», puesto que a menudo se utilizan ambos términos. La gamificación es entendida como el uso de elementos de los juegos 
en contextos no lúdicos (Deterding et al., 2011) y su principal diferencia con el aprendizaje basado en juegos digitales es que no hace uso de una experiencia de juego completa para lograr los resultados de aprendizaje perseguidos, sino que utiliza un pequeño número de elementos. Un ejemplo de gamificación sería la utilización de diferentes insignias dependiendo del resultado en un examen.

Los autores Perrota et al. (2013), como se muestra en el cuadro 1, establecen cuáles son los principios generales (conceptos subyacentes) y mecanismos (procesos y dinámicas que nos ayudan a entender cómo los juegos digitales pueden ayudar a la consecución de los objetivos educativos) que están implicados en el desarrollo de un juego digital enfocado en el aprendizaje.

Cuadro 1. Principios y mecanismos del aprendizaje basado en juegos digitales

Principios

Motivación intrínseca. Es una actividad voluntaria, y funciona mejor en un contexto de invitación y persuasión que en uno de obligación.

Aprendizaje a través de la diversión. Los juegos son un vehículo para atraer a los estudiantes y provocar estados de flujo.

Autenticidad. Hay una preocupación real por el aprendizaje, y las destrezas requeridas en el juego son destrezas coherentes con los objetivos perseguidos.

Autonomía. El juego incita a la exploración y al interés por sus elementos, de modo que se tiende a adquirir mayor conocimiento.

Aprendizaje experimental. Se aprende haciendo.
Mecanismos

Reglas. Modulan las consecuencias de las decisiones del participante.

Metas claras y desafiantes.

Un escenario ficticio o de fantasía.

Niveles de dificultad progresiva.

Interacción/alto grado de control del estudiante. Está relacionado con la noción de «agencia». El sentimiento de tener el control del destino de uno mismo.

Cierto grado de incerteza. No siempre debe existir una guía clara. Es posible dejar al participante la acción de descubrir cuál es la misión tras obtener algunas pistas.

Retroalimentación inmediata y constructiva. Es una herramienta esencial que permite al participante conocer su grado de desempeño.

Elemento social que permite a las personas compartir experiencias y construir lazos. El ecosistema que rodea al juego es importante y debe ofrecer a los participantes la oportunidad de compartir e interactuar con otros participantes.

El aprendizaje basado en juegos digitales tiene cada vez mayor aceptación en la comunidad educativa, principalmente por los resultados empíricos positivos que se están reportando 
en la última década. Por ejemplo, Hung et al. (2015) observan que, en comparación con grupos de estudiantes que siguen metodologías tradicionales, aquellos que estaban utilizando juegos digitales como herramienta educativa mostraron un mayor estado de flujo, desempeño en el aprendizaje y satisfacción. Por su parte, Liu et al. (2011) muestran una mejora en la adquisición de competencias de resolución de problemas. Finalmente, de forma más reciente, Elsherbiny y Al Maamari (2021) concluyen que grupos de estudiante bajo este tipo de metodologías tienden a mejorar su grado de aprendizaje.

Por otra parte, debemos destacar que existen infinidad de juegos digitales que podrían incluirse con la finalidad de cumplir los objetivos educativos perseguidos. La selección del tipo de juego y la herramienta para su diseño dependerá de tales objetivos y del conocimiento y creatividad del diseñador con las herramientas disponibles a su alcance. De modo que no hay límites. Es posible crear juegos digitales con una función educativa a través de aplicaciones con estructuras más limitadas, como Kahoot! o Socrative, pero también es posible diseñar juegos digitales abiertos y en 3D, con personajes, escenarios y un sinfín de acciones, con herramientas como Unity o Unreal Engine. En nuestro caso, y como comentaremos en epígrafes siguientes, nos enfocamos en un tipo de juego específico, el escape room, y cuyo desarrollo se materializa a través de la herramienta de diseño Genially.

\subsection{El escape room virtual: concepto, características y etapas de diseño}

En los últimos años, los escape rooms o juegos de escape se han convertido en una de las actividades de ocio mundialmente más populares (Villar-Lama, 2018). De acuerdo con Nicholson (2015), un escape room puede definirse como un juego en vivo basado en la interacción grupal a través del cual los participantes encuentran desafíos que deben superar para completar una misión en un limitado periodo de tiempo. Estas misiones pueden variar según el propósito de los diseñadores, de modo que pueden enfocarse en escapar de una habitación o incluso en la resolución de un caso de asesinato (Veldkamp et al., 2020).

Más allá de su función de entretenimiento, los educadores han visto el potencial que tienen este tipo de juegos en el ámbito educativo para el desarrollo de competencias como el trabajo en equipo, el pensamiento creativo, la comunicación, la gestión temporal, el control emocional, etc. (Wu et al., 2018). Por tanto, no es sorprendente que exista una tendencia creciente a incluir iniciativas de escape room en las programaciones docentes (Sempere-Pla, 2020).

De acuerdo con López-Pernas et al. (2019), a pesar de ser un elemento docente utilizado principalmente en etapas educativas primerizas

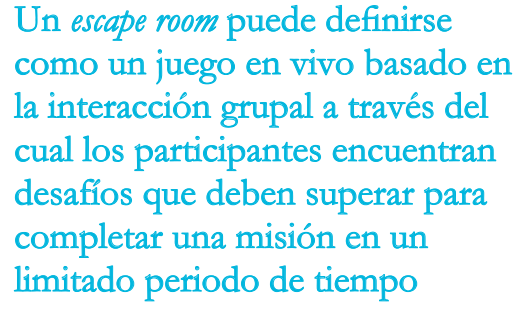

Un escape room puede definirse como un juego en vivo basado en la interacción grupal a través del cual los participantes encuentran desafíos que deben superar para completar una misión en un 
(primaria o secundaria), existe evidencia de la utilización de este tipo de juegos en centros universitarios en campos como la enfermería, la medicina o las matemáticas.

A continuación, vamos a determinar las principales etapas y características que deben tenerse en cuenta en el diseño y en la creación de un escape room digital con finalidad educativa. En nuestro caso, como desarrollamos en el apartado siguiente, seguimos las indicaciones de trabajos como López-Pernas et al. (2020) y Gómez (2020), los cuales señalan las etapas desarrolladas seguidamente:

\section{Etapa I. Elección de los objetivos}

En primer lugar, es necesario pensar cuáles son los objetivos de aprendizaje y competenciales que pretendemos abordar en la aplicación del escape room. Esta primera elección marca y guía los pasos venideros.

\section{Etapa II. Desarrollo de un hilo argumental}

Teniendo en mente los objetivos y el ámbito en el que se enmarca la asignatura (por ejemplo, tipo de alumnado, rama de conocimiento, semestre, etc.), es crucial pensar en una historia creativa, atractiva y con gancho para que los estudiantes tengan interés por su realización y se pueda lograr una experiencia inmersiva (López-Pernas et al., 2020). Por tanto, la historia tiene que estar conectada con lo que los estudiantes tratan de hacer y con los problemas o enigmas que se pretende que resuelvan. Es uno de los desafíos más grandes para el equipo diseñador, ya que un diseño poco atractivo probablemente repercuta negativamente en el éxito final del juego.

\section{Etapa III. Delimitación de aspectos generales}

Es importante pensar previamente en cómo el escape room va a ser implementado y experimentado por los estudiantes antes de comenzar su diseño. Por tanto, habrá que dar respuestas a preguntas tales como ¿cuál es la duración aproximada que tendrá el escape room?, ¿en qué enclave se va a celebrar?, ¿se plantea un escape room que pueda ser experimentado simultáneamente por los diversos grupos de estudiantes?, ¿qué material específico necesitan los estudiantes para la resolución de los enigmas?, ¿qué materiales se necesitan para crear el ambiente y dar cobertura al hilo argumentativo?, ¿es una actividad pensada para ser realizada en grupo o individual?, ¿cuál es el tamaño idóneo si es en grupo?, ¿qué tipo de escape room se va a plantear, es decir, competitivo, por tiempo, etc.?, ¿qué función tiene la actividad dentro de la asignatura?, ¿es una actividad voluntaria u obligatoria?, etc.

\section{Etapa IV. Selección de la aplicación o software para construir el escenario de escape room}

Existen numerosas herramientas para poder desarrollar nuestro escape room virtual, cada una de ellas con sus ventajas e inconvenientes. Por ejemplo, hay autores que han utilizado herramientas de Google, como Google Sites o Google Forms, para crear su escape room (Gómez, 2020). Otros utilizan herramientas más específicas, como Breakout Edu o Genially (Jiménez et al., 2020). Y, finalmente, hay quienes optan por herramientas con mayores posibilidades, como Unity (Bejarano et al., 2020). 


\section{Etapa V. Elección y construcción de los retos}

Conociendo los objetivos de aprendizaje, la temática, la delimitación de aspectos generales y la herramienta a través de la cual se diseña el escape room, es hora de seleccionar los retos que encajen con todo esto. Lo esencial es que cada reto integre mecánicas propias de un escape room, sus interrelaciones, y que se establezca correctamente cuál es la dificultad para completarlos. Entre los elementos típicos que componen los retos de un escape room podemos destacar los que aparecen reflejados en la figura I.

Figura I. Elementos frecuentes en un escape room

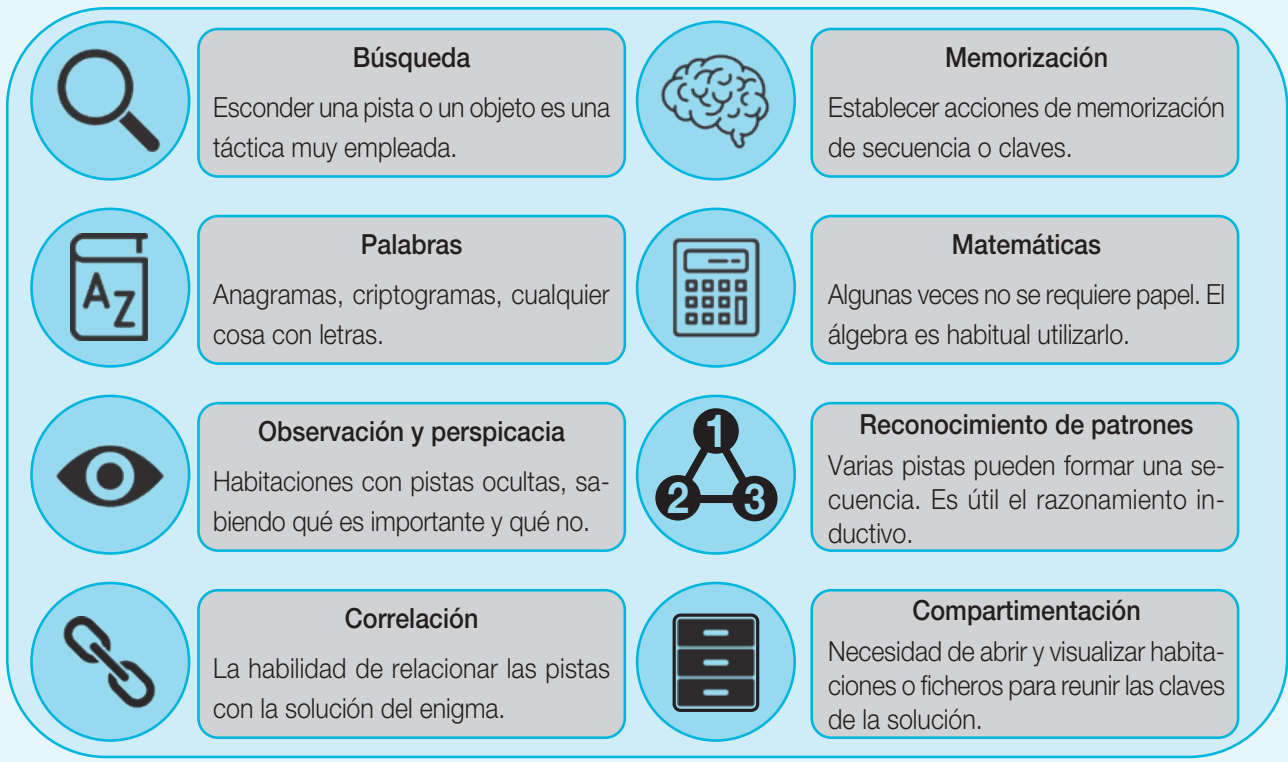

Fuente: adaptado de Wiemker et al. (2015).

Por otro lado, también es esencial seleccionar cuál será la secuencia en la resolución de los retos. Es decir, si es lineal, los retos siguen un orden específico en el que la solución de cada reto desbloquea el siguiente hasta llegar a la solución final. De acuerdo con López-Pernas et al. (2020), esta disposición puede ser más adecuada al contexto educativo porque fomenta que todos los miembros del equipo trabajen en conjunto para resolver cada reto. Lo habitual es que los primeros retos sean de dificultad menor. Conforme se van desbloqueando retos, la dificultad añadida se incrementa. No obstante, puede diseñarse una secuencia abierta, donde no hay un orden concreto, sino que para llegar a la solución final pueden abordarse las secuencias en el orden que el grupo de estudiantes considere oportuno. También podría, incluso, diseñarse una secuencia híbrida, donde algunos retos necesitan ser desbloqueados a través de retos más pequeños, pero que en la resolución final no exista un orden específico. 


\section{Etapa VI. Construcción de pistas}

Es una parte esencial en el diseño. Hay que prever que los alumnos pueden quedarse estancados en algún/os escenario/s y, si no reciben ayuda, el beneficio de la actividad se ve mermado al no poder enfrentarse a la totalidad de estos. A través de las pistas, damos facilidades a los estudiantes para superar estos retos (López-Pernas et al., 2020).

En este caso, podemos establecer dos categorías. La primera son pistas que el diseñador integra dentro del escenario del juego, y que de alguna manera sirven para dirigir al alumnado hacia la consecución de los retos. La segunda son pistas externas, que suele dar el game master (o director/a de juego). Para la obtención de las mismas se deberán establecer una serie de reglas. Por ejemplo, si la pista se puede solicitar tras un periodo de tiempo específico, si conlleva penalización temporal o de puntos o si es totalmente libre y sin ningún tipo de repercusión. Además, para evitar un uso abusivo de pistas, es habitual establecer un límite, generalmente dos.

\section{Etapa VII. Construcción de elementos de inmersión}

Este apartado es importante ya que determinará la profundidad del escenario y modulará el grado de inmersión que tendrán los participantes con el escape room virtual.

En definitiva, son elementos que, si los quitásemos, no afectarían a la resolución de los problemas, pero, con su inclusión, mejoramos el ambiente del escenario diseñado y, por tanto, la inmersión de los participantes.

\section{Etapa VIII. Elaboración de instrucciones}

Es importante que, antes de ejecutar el juego, se diseñen unas instrucciones precisas sobre el mismo. Entre las instrucciones más habituales se incluye información relativa a reglas de comportamiento, consecuencias de la superación de los retos, tiempo disponible para realizarlo, materiales necesarios, cómo solicitar pistas y sus repercusiones, etc.

Estas normas deben ser comprendidas y aceptadas por los participantes.

\section{Etapa IX. Testeo del escape room}

Esta etapa es vital, ya que, si no se lleva a cabo, lo más probable es que el juego llegue con defectos a los participantes, incluso defectos que pueden arruinar la experiencia del mismo.

Por tanto, es esencial que los diseñadores prueben el juego varias veces e incluso que otras personas ajenas al diseño y al estudiantado (por ejemplo, alumnos de cursos anteriores o profesorado de la misma materia) participen para dar opiniones, sugerencias e indicaciones de errores. Lo principal, evidentemente, es que los retos puedan superarse y no haya problemas en los mismos. 


\section{Diseño del escape room virtual}

\subsection{Objetivos generales del proyecto de innovación}

El propósito principal de la presente innovación era diseñar una herramienta docente que tuviera la capacidad de impactar positivamente en el aprendizaje de los estudiantes, principalmente en la retención de contenido, y en el desarrollo de ciertas competencias transversales, como el trabajo en equipo, la gestión emocional y la resolución de problemas.

Tras el análisis teórico, llegamos a la conclusión de que en la elección de la herramienta debía primar aquella que poseyera características intrínsecas capaces de fomentar en los estudiantes experiencia de flujo, ya que, a través de la misma, entendemos que la probabilidad de éxito en los objetivos de aprendizaje es mayor. Finalmente, se postuló como juego ideal el desarrollo de un escape room virtual, ya que, además de ser una herramienta digital y que fomenta la participación activa del alumnado, los beneficios y las competencias que comúnmente se suelen trabajar con este juego están estrechamente vinculados con los objetivos de aprendizaje perseguidos.

Por tanto, con esta innovación, pretendemos, concretamente, cumplir con los siguientes objetivos (véase figura 2):

- Diseñar un escape room virtual que tenga la capacidad de crear experiencias de juego de calidad en los participantes y, por tanto, estados de flujo.

- Profundizar en la herramienta de escape room y adquirir la experiencia necesaria para la elaboración de propuestas futuras.

- Analizar en qué medida el escape room virtual tiene un impacto en los objetivos de aprendizaje establecidos: retención de conocimiento y competencias transversales.

- Transferencia del conocimiento adquirido con esta propuesta, de modo que, por ejemplo, otros equipos docentes universitarios puedan tener una guía de actuación. 
Figura 2. Representación de los objetivos perseguidos y su relación

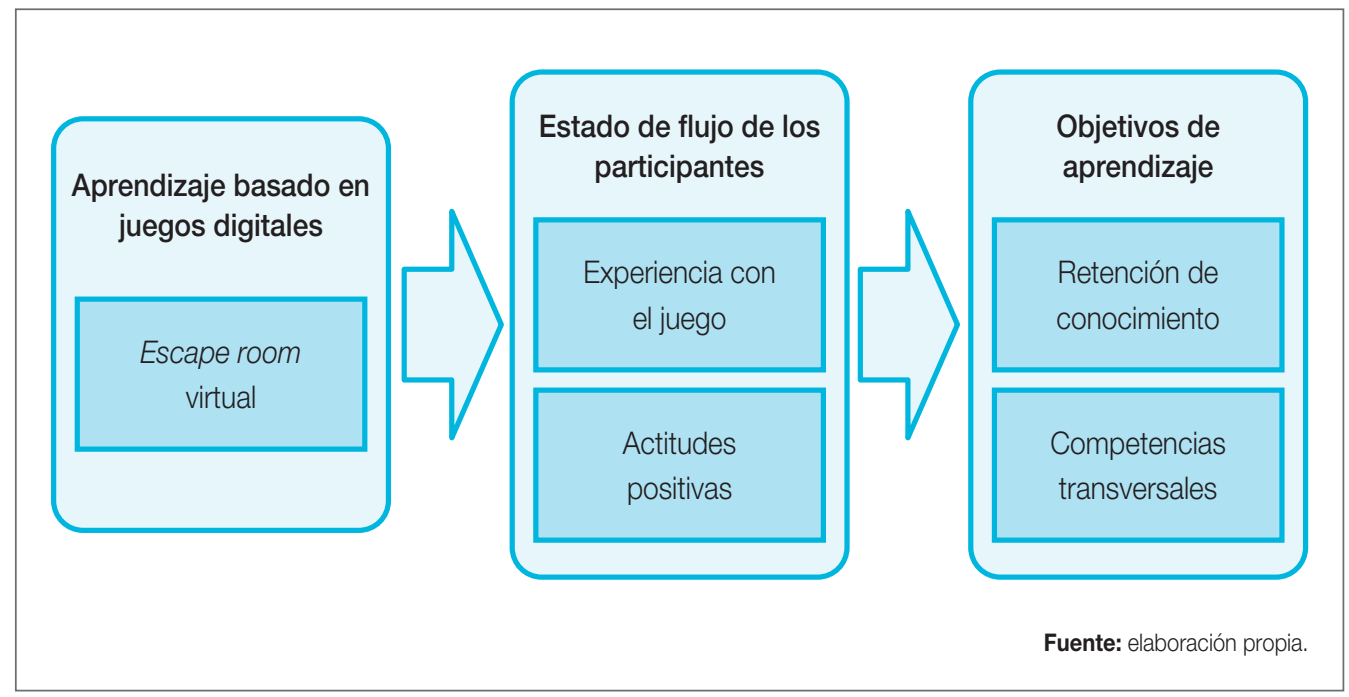

\subsection{Contexto del proyecto y objetivos específicos}

La aplicación de esta innovación tiene como destinatarios los 28 alumnos matriculados en la asignatura de Gestión de Calidad y Recursos Humanos del grado de Relaciones Laborales y Recursos Humanos de la Universitat Jaume I durante el curso académico 20202021. Los alumnos poseen manejo fluido de las tecnologías de la información. De hecho, en las actividades presenciales de la asignatura, el $100 \%$ de los asistentes llevan consigo algún tipo de dispositivo para el desarrollo de actividades, generalmente portátiles, y, en menor medida, tabletas e incluso teléfonos. La edad media de los alumnos es de 23 años. El alumnado tiene que hacer frente a esta y a otras asignaturas, al trabajo final de grado y a las prácticas curriculares.

El escape room se desarrolla a mitad de curso en una única sesión. La situación sanitaria de la COVID-19 y los protocolos seguidos por la universidad (aforo, espacio del aula, restricciones legales, etc.) permiten que la totalidad de los estudiantes asistan presencialmente al aula el día establecido para la realización del juego. Esta actividad pretende afianzar los principales conocimientos previos vistos hasta la fecha, de modo que, en las sesiones anteriores, el alumnado ha ido adquiriendo

\section{Esta actividad pretende afianzar} los principales conocimientos previos vistos hasta la fecha, de modo que, en las sesiones anteriores, el alumnado ha ido adquiriendo conocimiento y habilidad práctica necesaria para la resolución del escape room planteado 
conocimiento y habilidad práctica necesaria para la resolución del escape room planteado, tal y como discutiremos posteriormente. En concreto, pretendemos que a través del escape room se afiancen conocimientos y habilidades relativos a:

- La aplicación de herramientas de mejora continua: diagrama de Ishikawa1.

- Conocimiento de los elementos que debe integrar una política de calidad según la norma ISO 9001:2015.

- El cálculo del índice global de calidad ponderado de un servicio con la herramienta SERVQUAL ${ }^{2}$.

Por otro lado, pretendemos que, a través del escape room, el alumnado de la asignatura desarrolle, en un contexto lo más real posible, competencias transversales exigidas a futuros profesionales en el ámbito de la gestión de calidad. En concreto:

- Trabajo en equipo.

- Gestión emocional.

- Resolución de problemas.

\subsection{Desarrollo del hilo argumental}

El escape room virtual, titulado The Warehouse, tal y como se ilustra en la figura 3, se desarrolla bajo una temática de simulación en la que el alumnado debe ponerse en la piel de un miembro integrante de una consultoría ficticia. Este miembro tiene asociado tres misiones (o tareas de consultoría) que han sido solicitadas por una empresa de logística, también ficticia.

1 El diagrama de Ishikawa -también conocido como «causa-efecto» o «espina de pescado»- es una herramienta cuya función principal es la de clasificar y obtener ideas o hipótesis sobre las posibles causas de un problema de manera gráfica.

2 SERVQUAL es un cuestionario con 22 preguntas enfocadas a medir la calidad del servicio de cualquier organización. La herramienta fue desarrollada por Zeithaml, Parasuraman y Berry en 1985 y refinada en 1988.

De forma breve, podemos decir que, a través de la herramienta, se capturan las expectativas de los clientes con el servicio y sus percepciones finales una vez consumido el mismo. Las dimensiones que se miden son la fiabilidad del servicio, los elementos tangibles, la capacidad de respuesta, la seguridad y la empatía. La distancia entre las expectativas y las percepciones determina la calidad del servicio. 
Figura 3. Título e hilo argumental
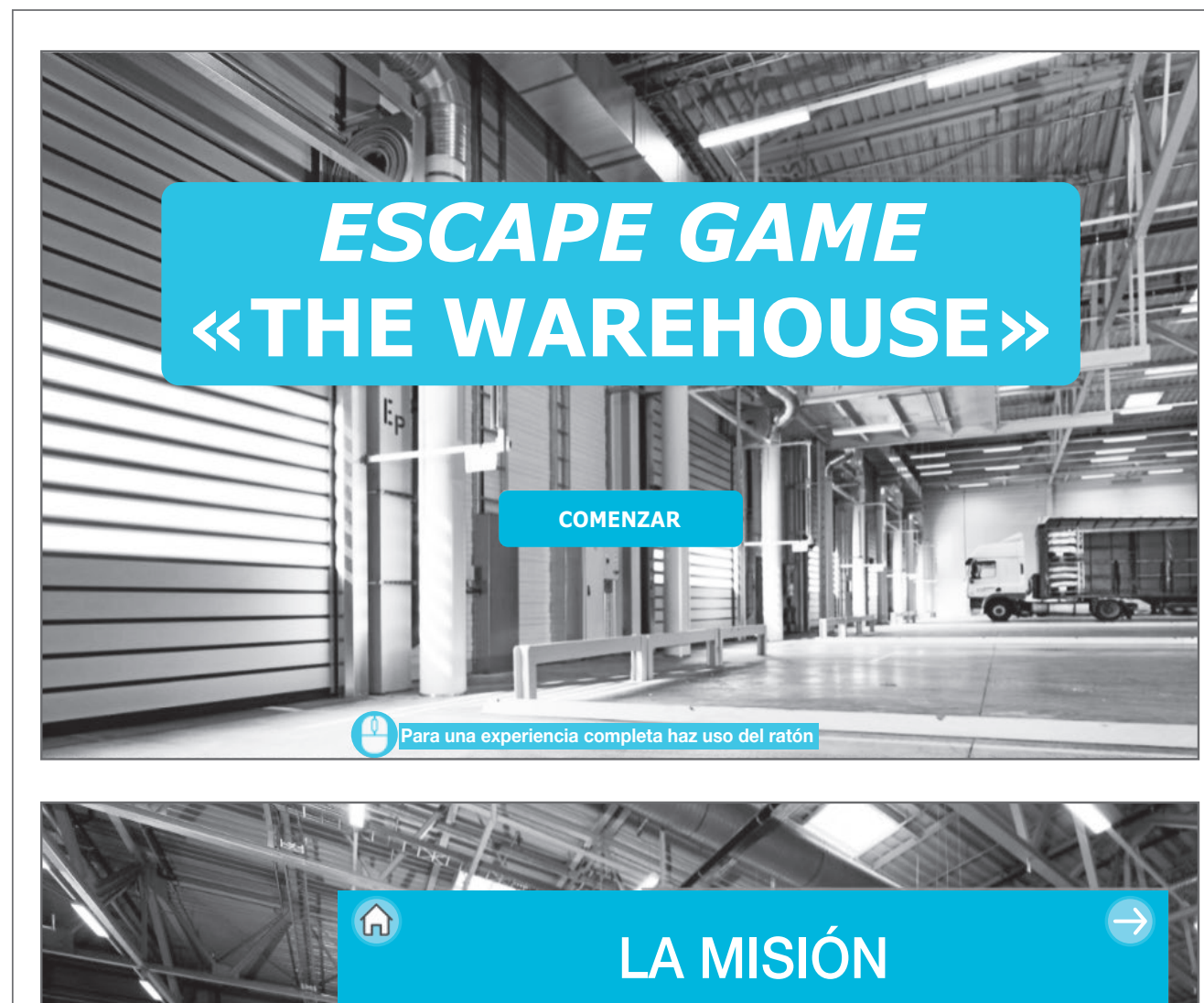

LA MISIÓN (I): La empresa LogisticPro Cooperative es una empresa de reciente creación dedicada a la recepción y reparto de mercancías, cuyos servicios se dirigen especificamente a otras organizaciones. Como consecuencia de la pandemia de 2020-2021, la demanda de sus servicios se cuatriplicó en apenas tres meses. Con el fin de satisfacer toda la demanda, la empresa tuvo que expandirse muy rápido. La consecuencia de ello es la aparición de deficiencias en algunos procesos, descontento de algunos clientes y perjuicio para la imagen corporativa.

La dirección de LogisticPro Cooperative ha contratado a un equipo de gestión de calidad con el fin de solventar algunos de los problemas en su gestión. La directora de calidad, Marta Garriga, tiene como principal objetivo mejorar la satisfacción del cliente introduciendo herramientas de gestión de calidad, como, por ejemplo, la implantación de la norma ISO 9001:2015. Además, con el fin de mejorar la imagen corporativa, otro objetivo sería poder certificarse. 

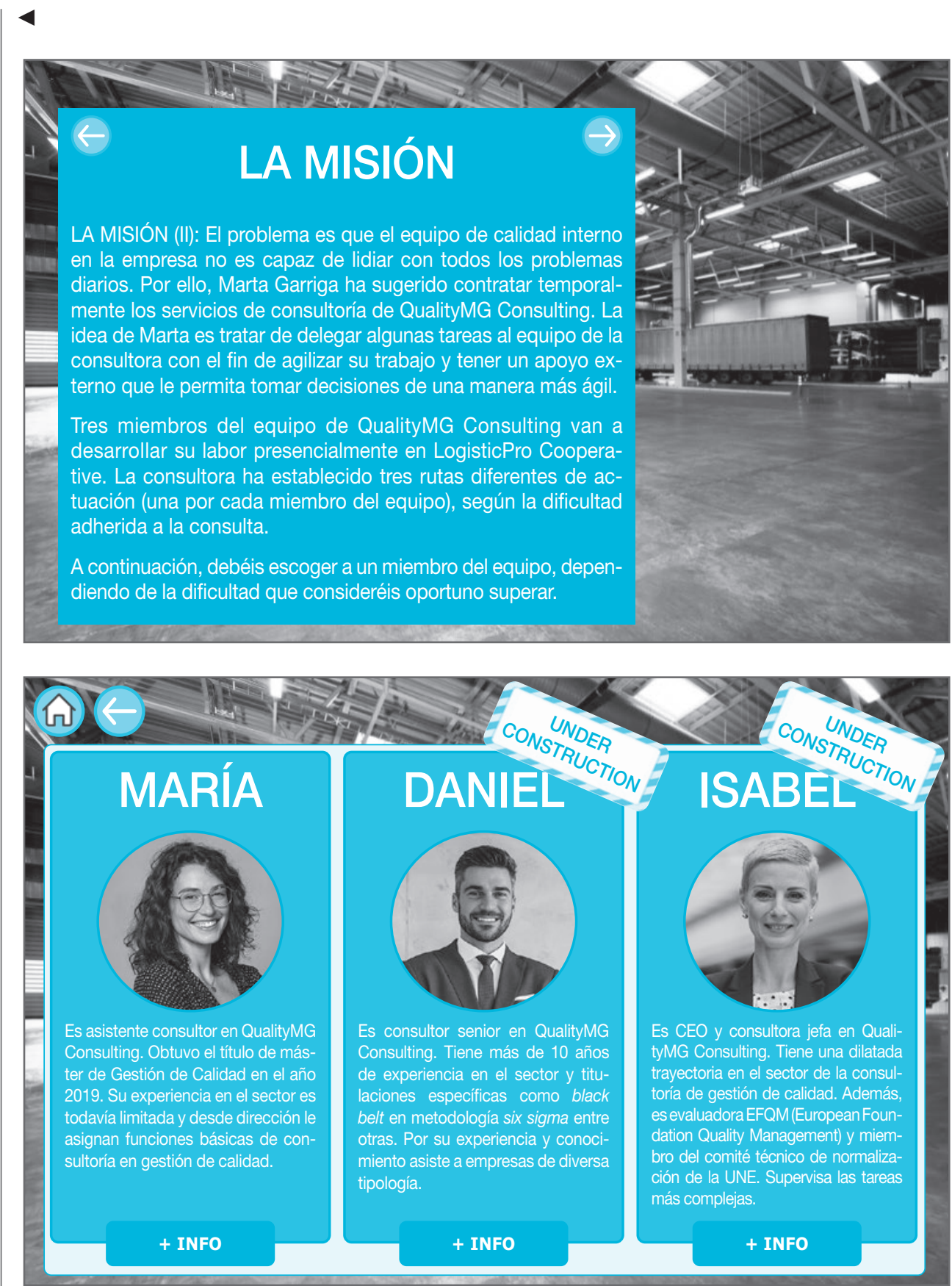

Fuente: extraído del editor de Genially. 
Estas tres misiones, dedicadas a cada uno de los objetivos de repaso de conocimiento (política de calidad, herramienta de mejora continua y cálculo del índice de calidad ponderado SERVQUAL) deberán resolverse en las instalaciones de la empresa logística. Como se observa en la figura 3, las posibilidades futuras del juego son ampliar otras dos rutas de misiones. Es decir, que los participantes, en años posteriores, puedan escoger entre tres miembros consultores con distintas misiones cada uno de ellos y diferentes modalidades de dificultad.

\subsection{Determinación de los aspectos generales del juego}

El escape room virtual, por sus posibilidades, se puede concretar para que sea desarrollado tanto en las instalaciones de la universidad como virtualmente. En la experiencia aquí mostrada, el escape room tuvo lugar en el aula habitualmente designada. Dado que era la primera experiencia con un grupo de estudiantes, y teniendo en cuenta las posibilidades de seguridad sanitarias y las instalaciones del aula (enchufes, disposición de las mesas, sillas, espacio entre sillas, ventilación, etc.), se apuesta por desarrollarlo presencialmente, de modo que, ante cualquier error o bloqueo, la subsanación del mismo o la incomprensión en algún detalle pueda tratarse de forma más ágil.

Otro aspecto que determinamos es la simultaneidad de los grupos en la ejecución del juego. Dado que todos los miembros pueden acceder al juego a través de un enlace, no hay impedimentos de espacio ni concurrencia de participantes. Para dotar de un elemento de presión propio del escape room, en nuestro caso seleccionamos la competitividad. Es decir, los tres primeros grupos en terminar tienen asociadas bonificaciones en la nota. La actividad tiene peso en la nota de la asignatura, aunque, simplemente por terminarla, el grupo de estudiantes recibirá la máxima nota.

Por otro lado, no optamos por un elemento de presión como el tiempo, por no tener una referencia de experiencia anterior con la aplicación del juego, y, quizá, establecer un tiempo mal calculado (muy amplio o muy reducido) podría mermar la experiencia de juego. No obstante, en todo momento se tiene presente establecer que el juego pueda ser superado en un máximo de 60 minutos.

El juego tiene carácter grupal, preferiblemente de tres participantes, pero aceptando que existan grupos de entre dos y cuatro integrantes. Los alumnos vienen trabajando en grupos consolidados. Cambiarlos, por el hecho de tener un número rígido de integrantes en el juego, puede suponer la emergencia de cierta resistencia, actitud que pretendemos evitar. Cada integrante puede entrar al juego a través del enlace e ir descubriendo pistas del escenario. La intención es que de forma autónoma se gestione la forma de proceder y que no se establezcan límites de comportamiento, de modo que un miembro pueda descubrir una pista y comunicársela al resto de integrantes para resolver la misión final o que, entre todos, puedan ir escenario por escenario recopilando las mismas pistas y poniéndolas en común. 
Finalmente, consideramos que el estudiante puede utilizar los siguientes elementos para dar solución a los enigmas: una calculadora para el cálculo del índice de calidad ponderada (aunque puede ser a través del móvil u ordenador), el propio ordenador o tableta para jugar al juego y un lápiz o un boli para anotar pistas o deducciones. En este caso, es esencial para la experiencia de juego que los participantes tengan un ratón o que su portátil o tableta disponga de touchpad, de modo que puedan activar las funcionalidades de interactividad del puntero. Estos elementos los pueden llevar todos los estudiantes de manera que la actividad no implique un esfuerzo económico para el equipo docente.

\subsection{Selección de la aplicación o software}

Para el desarrollo del escape room utilizamos Genially. Consideramos que esta herramienta con finalidad docente cumple con una serie de parámetros para poder desarrollar nuestro juego con garantías. A modo de resumen, las ventajas que observamos en esta aplicación son las siguientes:

- El concepto de escape room o breakout está integrado en su plataforma, de modo que existen tutoriales, blogs, plantillas y una comunidad con experiencia. Estos elementos son de ayuda ante cualquier problema en el diseño.

- La herramienta de creación es totalmente gratuita (aunque existen planes premium con algunas funcionalidades) e intuitiva y permite trabajar online, de modo que el trabajo desarrollado queda en la nube y no se pierde.

- Es muy sencillo integrar funciones de otras aplicaciones a través del código html, por lo que las posibilidades se amplían. Por ejemplo, podemos insertar un mapa a través de Google Maps o un vídeo subido a Google Drive.

- Se puede compartir con facilidad el escape room creado a través de un enlace permanente.

- Permite la interactividad entre elementos y páginas. Es decir, podemos establecer que un elemento (puerta) incluido en una página específica (una habitación) conduzca a otra página específica (otra habitación). O, incluso, podemos establecer que un elemento oculto por el mapa (hoja) se resalte al pasar el ratón por encima. Las posibilidades de interactividad son tantas que establecer la profundidad del juego depende de la capacidad del diseñador.

En la figura 4 se muestra un pequeño ejemplo de interactividad de nuestro juego. Cuando el participante hace clic en alguna zona de las que indicamos en la figura (por ejemplo, la estantería), le conduce a la imagen enlazada (por ejemplo, los libros). El resultado pretendido, en este caso, es que el participante tenga la sensación de estar explorando con más detalle una parte de la habitación. Para que esta acción sea más intuitiva, cuando 
el participante desliza el puntero del ratón por alguna zona interactiva, establecemos que la zona se resalte, que aparezca un texto o que cambie el icono del puntero por el de una mano.

Figura 4. Interactividad entre elementos

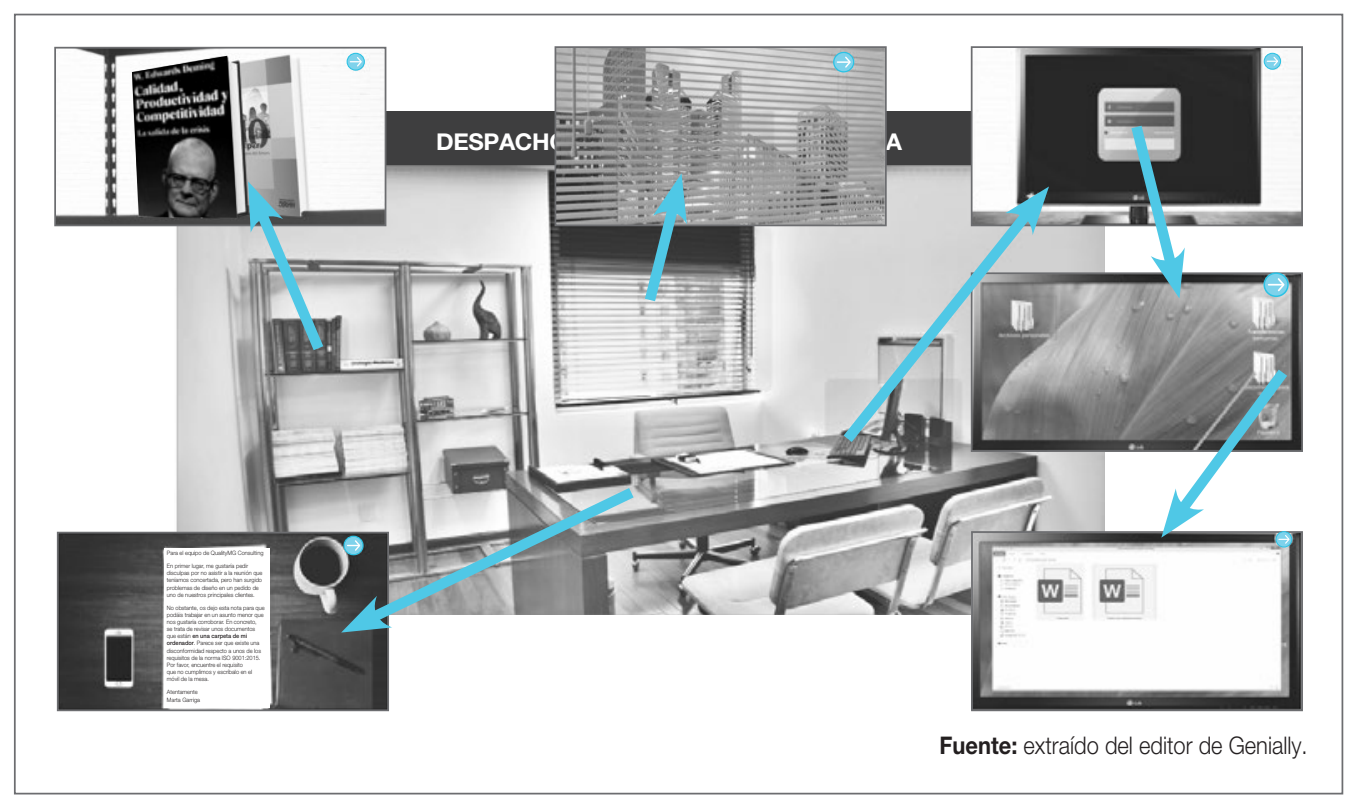

\subsection{Selección y creación de los retos}

En este apartado, de forma detallada, vamos a describir los tres retos integrados en la primera ruta de elección y que están vinculados con los objetivos de aprendizaje y competenciales perseguidos.

\section{A) Hilo argumental de la primera misión}

En esta misión, los participantes, tomando el rol de un miembro de una consultoría ficticia, deben acudir a las oficinas de la empresa logística, encontrar a la directora de calidad y tratar de resolver un problema relacionado con la implantación de la norma ISO 9001:2015. Una vez dentro de las oficinas, los participantes exploran el primer gran escenario, donde hay varios empleados que, al interactuar con ellos, dan cierta información relevante para resolver la misión. Por ejemplo, uno de los empleados hace alusión a la falta de comunicación de algunos puntos de la política y objetivos de calidad. Por otro lado, los participantes, a partir de este primer escenario, pueden lograr acceder al despacho de la directora (véase 
figura 4), segundo gran escenario, y, si lo desean, volver atrás. Una vez que acceden al despacho, hay diversos elementos interactivos. Los más relevantes son los siguientes:

- Estantería con un libro de Edward Deming.

- En la mesa hay dos elementos principales (véase figura 5). En primer lugar, hay una nota de la directora, indicando qué es lo que solicita del equipo de la consultoría y disculpándose por no asistir. En concreto, solicita que el equipo identifique qué requisito de la norma ISO 9001:2015 no cumplen. Para ello deberán ir al ordenador. En segundo lugar, hay un móvil. Una vez que los participantes tienen claro el requisito que no se cumple, deberán indicarlo en el móvil. Si es correcto, acceden a la segunda misión. Si no es correcto, pueden volver a cualquier parte del escenario y tratar de recoger información.

- Ordenador de la directora. Para acceder al mismo hay que escribir una contraseña (Deming). A modo de pista, en la pantalla hay un pósit que indica lo siguiente: «Password PC: apellido de un gurú de calidad».

- Dentro del ordenador, tras una búsqueda entre las carpetas, hay dos archivos que se pueden revisar. El primero es una política de calidad de la empresa, la cual desarrollamos y enlazamos a través de Google Docs. El segundo es un checklist con los principales elementos que debe cumplir la política de calidad y su comunicación en la empresa, acorde a la norma ISO 9001:2015.

Figura 5. Elemento final de la primera misión

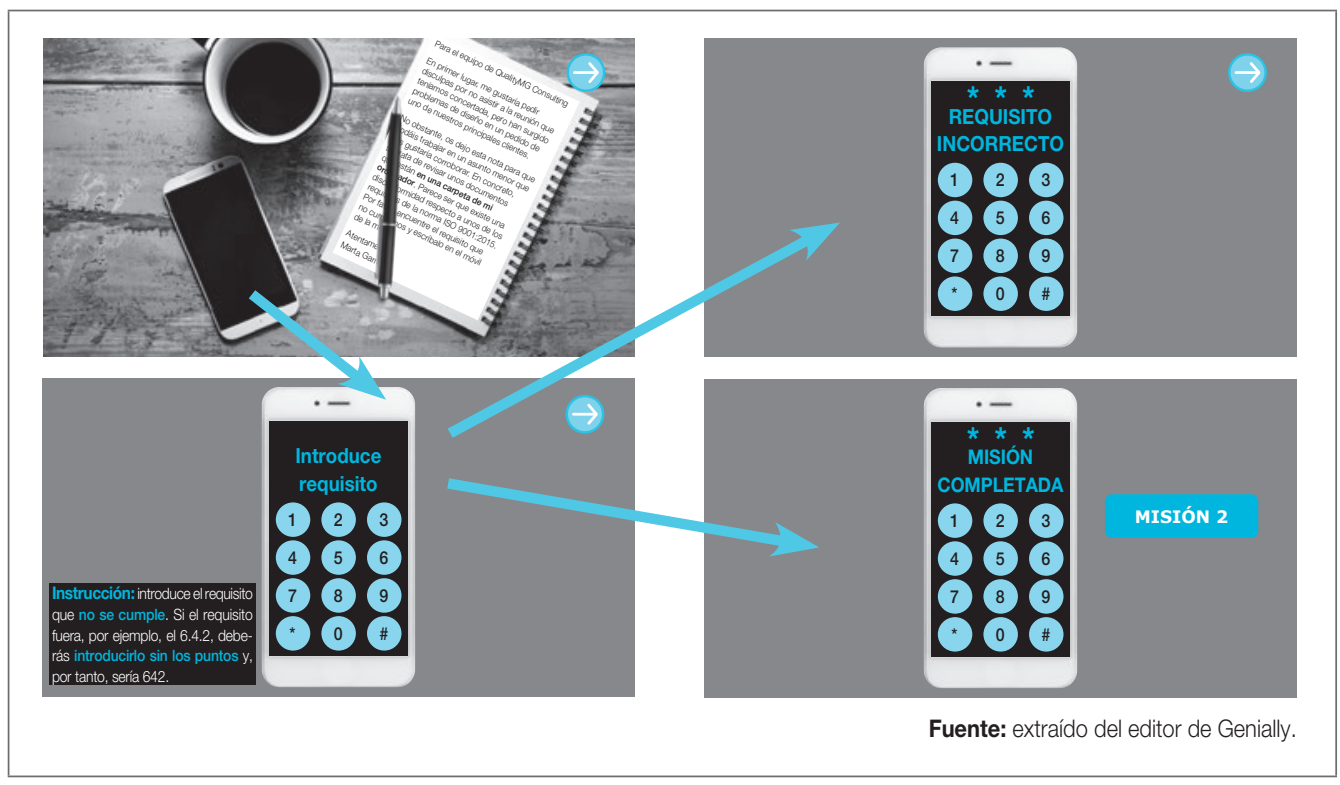




\section{B) Hilo argumental de la segunda misión}

En esta misión, los participantes acuden a la zona operativa de almacenaje de la empresa y deben asistir a la empresa aplicando correctamente una herramienta de mejora continua (el diagrama causa-efecto o espina de pescado). Para ello, los participantes tendrán que encontrar al encargado de la zona y obtener información más detallada sobre cuál es el problema, de modo que puedan establecer las causas y aplicar la herramienta. En el escenario de partida, exploran los distintos pasillos del almacén (véase figura 6). Cada uno de estos pasillos tiene información relevante para solventar la misión. Por ejemplo, en el pasillo central hay una puerta con clave y para abrirla es necesario interactuar con el encargado, que está en el pasillo que se indica con la flecha negra. El encargado, tras poner a prueba a los participantes con varias preguntas sobre gestión de calidad, proporcionará la clave de la puerta y el problema concreto que existe (averiguar las causas que hay detrás de continuos errores en el almacenamiento de productos). Para establecer las causas, los participantes deben explorar todo el mapa, tanto en la zona de almacenaje como en la zona de reuniones, es decir, la zona a la que se accede tras poner la clave en la puerta.

Figura 6. Escenarios en la segunda misión

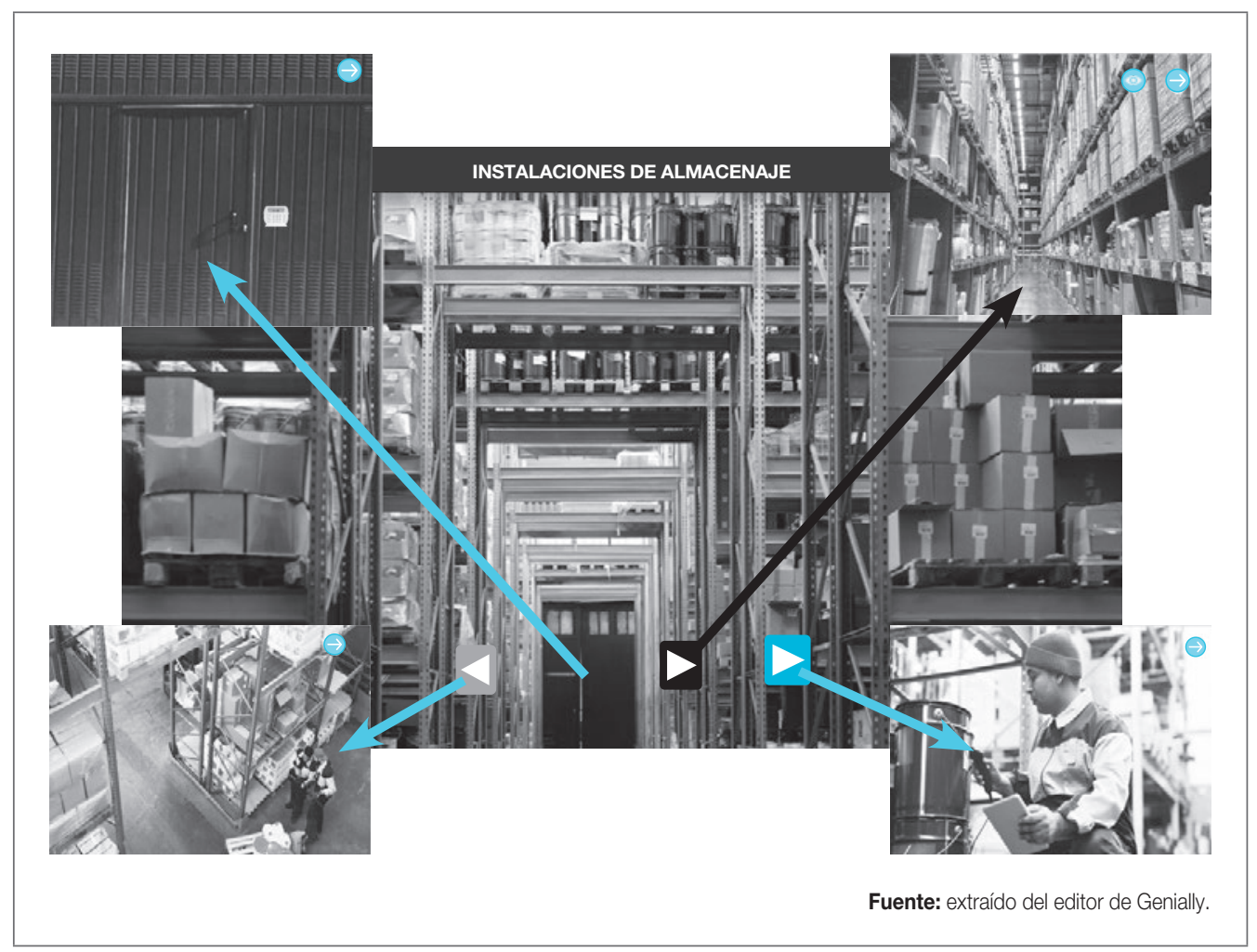


En la zona de reuniones (véase figura 7) hay varias estancias con información relevante, pero, en concreto, hay una donde se ubica el elemento (una pizarra de pie) en el que se debe aplicar la herramienta de causa-efecto para establecer las causas del problema. Los participantes, tras la exploración por la zona de reuniones y por la zona de almacenaje habrán podido observar que hay elementos (en total 14) en los que al pasar el ratón por encima se abre automáticamente un texto que indica el estado del elemento concreto y un código identificativo del mismo. Estos elementos están estrechamente relacionados con las posibles causas del problema. Por ejemplo, en la figura 6 , el operario está utilizando una pistola de código. Cuando los participantes pasan el ratón por encima, salta un mensaje que indica lo siguiente: «Es una pistola de código bastante desactualizada, por cierto. Parece que hay una numeración en su reverso (C 12)»

Figura 7. Más escenarios en la segunda misión

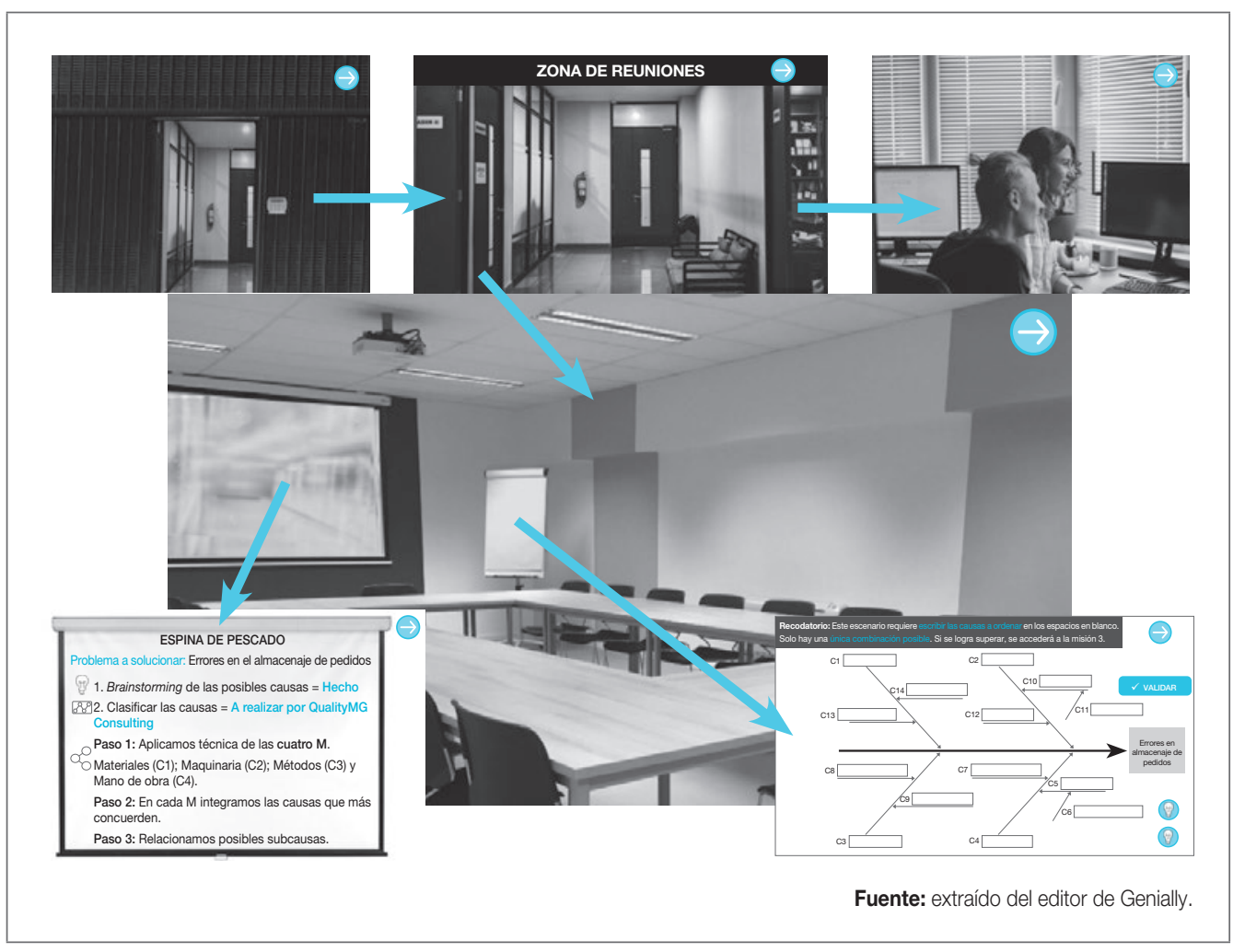

Con la recopilación de estos códigos, los participantes pueden dar con todas las causas y completar la misión al establecer la combinación única requerida. Como se observa en la parte inferior derecha de la figura 7 , las causas que se han ido recopilando deben escribirse en los huecos de la imagen. En total hay 14 huecos para 14 causas. Por tanto, los 
participantes, en primer lugar, deben recopilar todas las causas y los códigos para, posteriormente, ir rellenando los huecos de acuerdo con la metodología 4 M (materiales, maquinaria, métodos y mano de obra).

\section{C) Hilo argumental de la tercera misión}

En esta misión, los participantes acuden al departamento de ventas de la empresa. El objetivo es conocer el índice de calidad global del servicio ponderado. Para obtener los datos y hacer los cálculos SERVQUAL deberán hablar con el director del departamento. En el primer escenario, los participantes pueden obtener información de una empleada sobre el paradero del director comercial, y, por otro lado, acceder a su despacho. En el despacho, escenario final para la resolución del problema, los participantes, indagando en el mismo, obtendrán información para resolver la misión. De forma resumida, la información que hay en el despacho es la siguiente (véase figura 8):

- Grabadora. A través de ella, los participantes pueden escuchar un mensaje que el director ha dejado para ellos explicando con detalle lo que se requiere.

- Nota 1. En esta nota, situada sobre la mesa, el director indica que, cuando estén en su despacho, le escriban un correo electrónico (a una dirección señalada en la nota) para obtener los pesos ponderados de cada dimensión SERVQUAL. A través de la función de Gmail, se pudo establecer que, al recibir un correo electrónico, se enviara un mensaje automáticamente al remitente. En este caso, el mensaje automático son los pesos de las dimensiones, de modo que se crea un efecto de conexión con un personaje ficticio.

- Nota 2. En esta nota, situada sobre la mesa, el director les indica a los participantes que, por seguridad, ha dejado un código QR en el abrigo del despacho y que, a través del mismo, podrán acceder a los resultados medios obtenidos por cada ítem. Cuando los participantes utilizan el móvil para captar el código QR, aparece un enlace a Google Docs, donde encuentran esta información.

- Ordenador. A modo de pista, en el ordenador, los participantes pueden observar un ejemplo en relación con la parte final del cálculo.

- Código QR. Como hemos señalado, se encuentra en el abrigo.

- Tableta. En este elemento, los participantes deben escribir los cálculos de las brechas entre expectativas y percepciones para cada dimensión y, posteriormente, escribir el índice global ponderado de la calidad del servicio. A modo de pista, en la parte derecha ofrecemos una serie de números, entre los cuales se encuentran los dígitos que deben escribirse. Cuando los participantes ingresan correctamente todos los números, el juego finaliza con éxito. 
Figura 8. Escenarios y elementos en la tercera misión

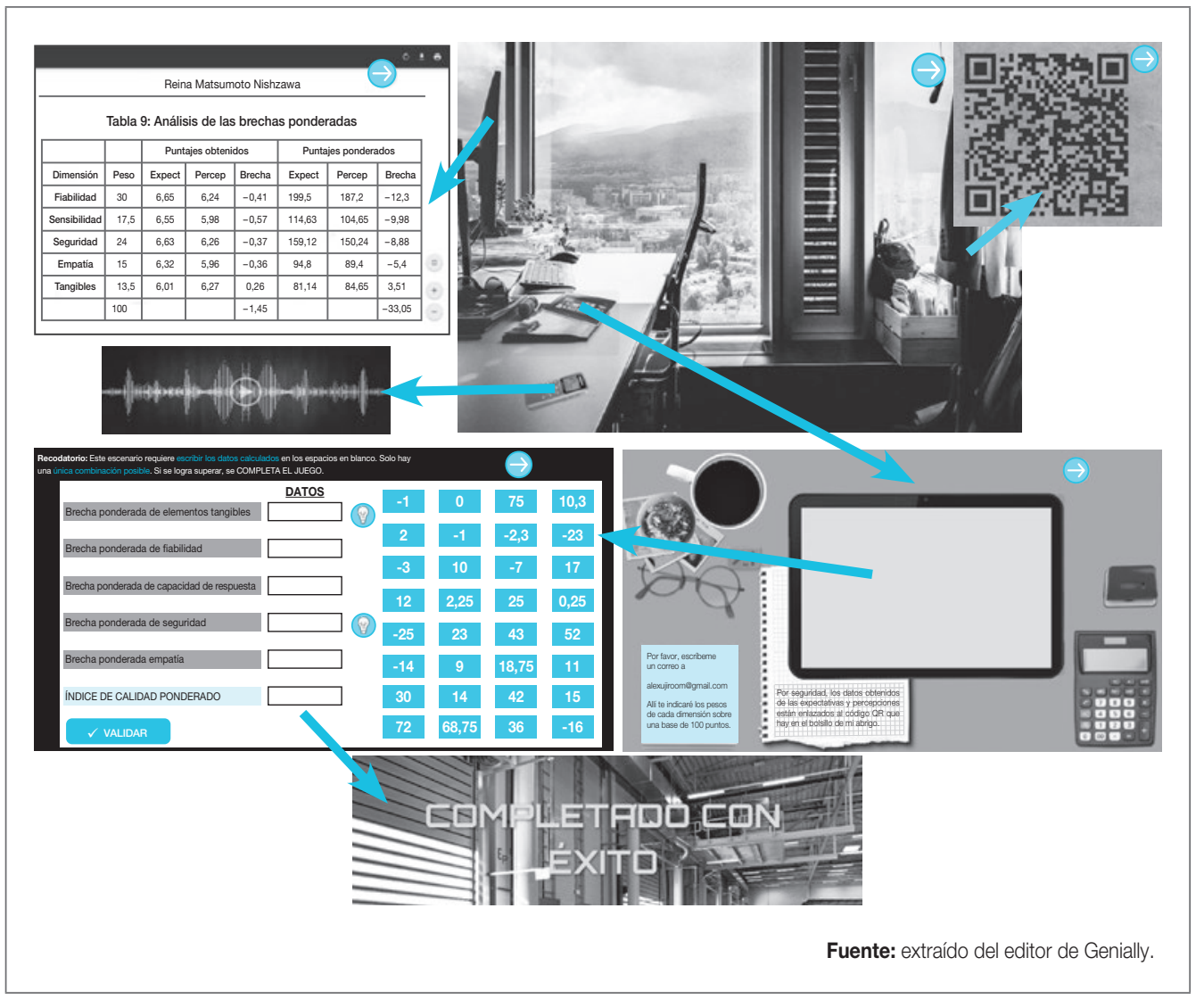

\subsection{Construcción de pistas}

Las pistas que hemos introducido dentro del juego virtual las podemos catalogar de dos tipos:

- Pistas in game de resolución de retos. Estas pistas son, en realidad, pequeños elementos que los participantes descubren por el escenario y que facilitan la resolución de algún enigma. Sin ellas, el enigma podría ser resuelto, pero sería mucho más complicado.

- Pistas in game de desbloqueo. Estas pistas son esencialmente iconos a través de los cuales se establecen directrices que pueden servir para aquellos participantes que se han quedado bloqueados en alguna pantalla. 


\section{Cuadro 2. Relación de pistas ingresadas en el juego}

\begin{tabular}{|c|c|c|}
\hline & Pistas in game de resolución de retos & Pistas in game de desbloqueo \\
\hline \multirow{4}{*}{ Misión 1} & \multirow{4}{*}{$\begin{array}{l}\text { Libro de Edward Deming para introducir la } \\
\text { contraseña en el ordenador. } \\
\text { Pósit indicando la temática de la contraseña. }\end{array}$} & Instrucciones sobre cómo utilizar el móvil. \\
\hline & & Recordatorios en relación con que la solu- \\
\hline & & $\begin{array}{l}\text { ción se establece obteniendo información } \\
\text { de documentos, trabajadores, etc. }\end{array}$ \\
\hline & & $\begin{array}{l}\text { Recordatorios sobre cómo funcionan partes } \\
\text { del juego, como el uso del ratón, etc. }\end{array}$ \\
\hline \multirow{4}{*}{ Misión 2} & \multirow{4}{*}{$\begin{array}{l}\text { Mensaje de móvil que los participantes reci- } \\
\text { ben indicando la importancia de anotar los } \\
\text { códigos que hay por el escenario. } \\
\text { Pantalla de proyector con las instrucciones } \\
\text { que el grupo de trabajadores había segui- } \\
\text { do para realizar el diagrama causa-efecto. } \\
\text { Cada causa tiene asignado un código, y ese } \\
\text { código está puesto en la pizarra de pie. La } \\
\text { relación de códigos y causas la pueden ob- } \\
\text { tener indagando por el mapa. }\end{array}$} & $\begin{array}{l}\text { Instrucciones sobre cómo introducir los } \\
\text { datos en la pantalla final del reto: respetar } \\
\text { los acentos y los espacios de las palabras. }\end{array}$ \\
\hline & & $\begin{array}{l}\text { Recordatorio de la contraseña de la puerta. } \\
\text { Una vez que el encargado les da las instruc- } \\
\text { ciones, desaparece del juego y, por tanto, }\end{array}$ \\
\hline & & $\begin{array}{l}\text { pueden ir por el escenario, pero ya no vuel- } \\
\text { ven a entablar conversación con él. }\end{array}$ \\
\hline & & $\begin{array}{l}\text { Recordatorios sobre el hecho de que por el } \\
\text { mapa hay códigos ocultos y son necesarios } \\
\text { para completar la misión de forma rápida. }\end{array}$ \\
\hline \multirow{3}{*}{ Misión 3} & \multirow{3}{*}{$\begin{array}{l}\text { En la pantalla del ordenador hay una ima- } \\
\text { gen que muestra un ejemplo de cálculo. } \\
\text { Supuestamente, se la deja abierta el di- } \\
\text { rector. } \\
\text { Grabadora que pueden utilizar los partici- } \\
\text { pantes para escuchar las instrucciones del } \\
\text { director. }\end{array}$} & $\begin{array}{l}\text { Instrucciones sobre cómo pueden introdu- } \\
\text { cir los cálculos, respetando las comas, los } \\
\text { espacios, etc. }\end{array}$ \\
\hline & & $\begin{array}{l}\text { Instrucciones sobre cómo utilizar la tableta } \\
\text { y enviar el correo electrónico. }\end{array}$ \\
\hline & & $\begin{array}{l}\text { Instrucciones sobre los pasos necesarios } \\
\text { para el cálculo del índice ponderado. }\end{array}$ \\
\hline
\end{tabular}

Fuente: elaboración propia.

Por otro lado, también establecemos la posibilidad de solicitar ayuda al game master cuando algún equipo pueda quedarse bloqueado en una misión. Los requerimientos para solicitar asistencia son los siguientes:

- Solamente es posible solicitar una asistencia por misión. El game master valora la situación de bloqueo e indica una directriz para que puedan seguir investigando y reflexionando sobre la posible solución.

- La asistencia se solicita pasados 20 minutos desde el comienzo de la misión en concreto. Con esta medida se pretende que los participantes agoten todas las 
posibilidades que existen de indagar por el escenario y la puesta en común del reto. El game master va anotando el tiempo de resolución de retos por parte de los participantes, de forma que tiene ese control.

\subsection{Construcción de los elementos de inmersión}

Como hemos señalado en el epígrafe 2.3, los elementos de inmersión son aquellos que, en sí mismos, no son imprescindibles para resolver los retos, pero que dotan de profundidad al juego.

A continuación, establecemos la siguiente clasificación de los elementos de inmersión introducidos:

- Acceso a puertas, ventanas, ficheros y elementos del escenario. En cada escenario tratamos de introducir el máximo número de elementos a través de los cuales los participantes puedan tener acceso para indagar sobre ellos y, en definitiva, disfrutar con su exploración.

- Imágenes. La construcción de los escenarios se realiza a partir de imágenes sin copyright procedentes de bancos específicos, como Pexels. Las imágenes son de alta definición. Además, se utilizan imágenes en formato .PNG para insertar elementos en capas superiores al fondo establecido y poder completar el escenario.

- Música. Para dotar de una mayor tensión al juego, hemos introducido un ambiente musical de corte instrumental (el participante lo puede encender o apagar).

- Transición entre páginas. Cada página representa una imagen concreta que los participantes van a visualizar. Cuando los participantes desean, por ejemplo, cruzar una puerta, deben hacer clic en la puerta para pasar a otra imagen, que, en general, es la representación de otra estancia. Dependiendo del efecto que queremos crear, seleccionamos un estilo de transición u otra.

- Movimiento de todos los elementos. Dependiendo del elemento de la página, aplicamos una serie de movimientos $u$ otros en consonancia con lo que queremos representar. En resumen, podemos establecer los movimientos que se establecen en el cuadro 3.

- Composición del entramado de páginas. A mayor número de páginas, mayor profundidad del juego. En nuestro caso, hemos elaborado un total de 80 páginas, todas con interconexión entre sí. Algunas incluso con 6 o 7 conexiones. 


\section{Cuadro 3. Elementos incluidos en el juego con movimiento}

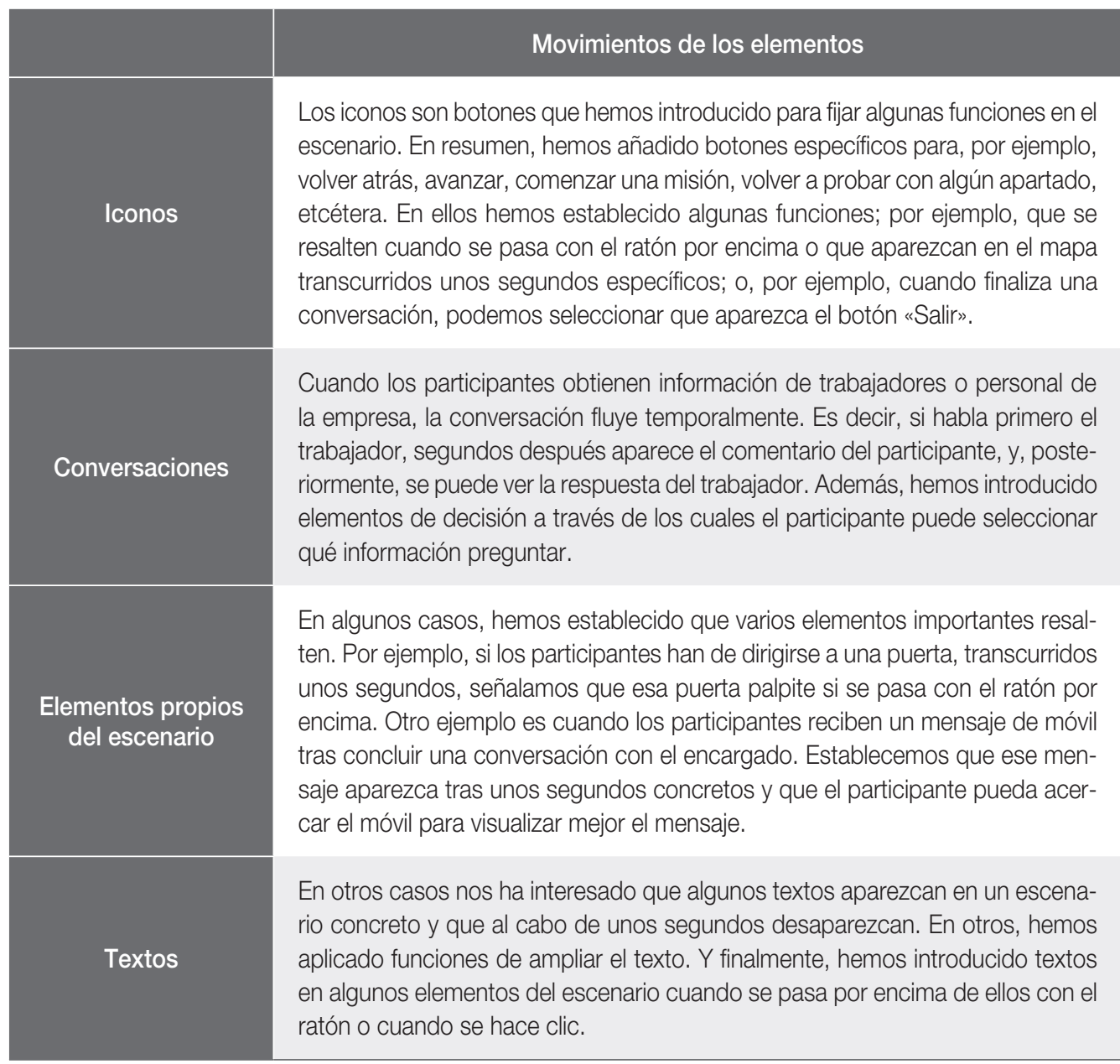

Fuente: elaboración propia.

\subsection{Elaboración de las instrucciones}

Al inicio del juego se establecen las instrucciones o informaciones de interés relevantes con la propia experiencia de juego (véase figura 9). No obstante, antes de comenzar la partida, el game master explica con el proyector de clase instrucciones más precisas, especialmente con la solicitud de pistas. También introduce cuál es la temática del escape room, explica el funcionamiento de un escape room para aquellos alumnos que nunca hayan experimentado el mismo y resalta los objetivos perseguidos con el juego. 
Figura 9. Instrucciones al inicio del juego

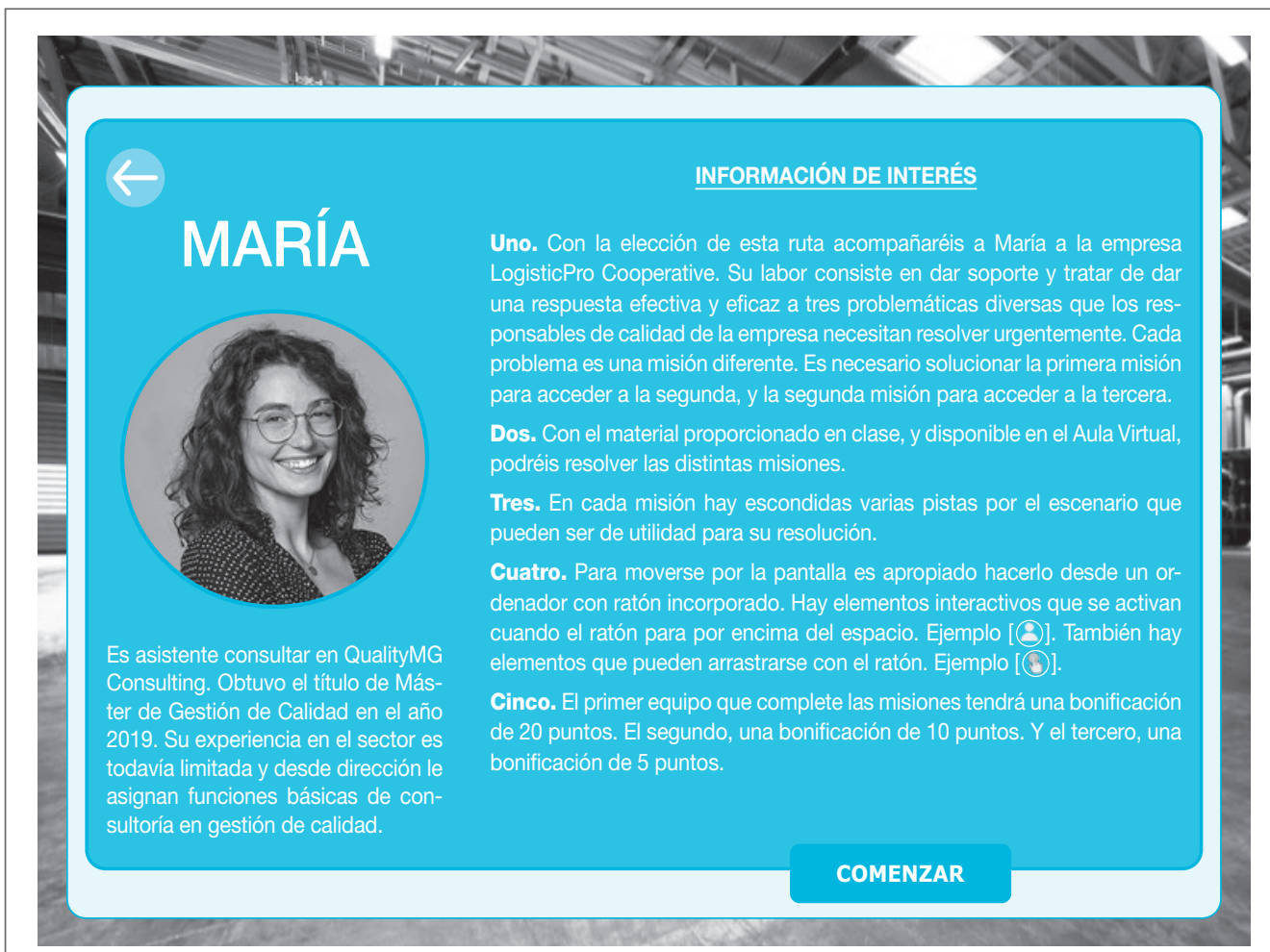

Fuente: extraído del editor de Genially.

\subsection{Testeo del escape room}

El equipo docente realizó, aproximadamente, cerca de 15 revisiones tras completar, por primera vez, el diseño del juego. Las primeras revisiones se enfocaron en comprobar que los elementos principales para resolver las misiones funcionaban y que no había ninguna conexión entre páginas erróneas o alguna otra función fallida. Esto era importante porque cualquier conexión errónea repercutía directamente en el bloqueo del juego y en el fracaso de la experiencia. Además, con estas revisiones se fueron puliendo pequeños elementos; por ejemplo, los segundos requeridos hasta que aparecía un elemento, la información que debía incluirse en un botón concreto, etc.

Comprobando que estas funciones eran correctas, el siguiente paso fue probar el juego con jugadores externos que no tuvieran ningún tipo de conocimiento sobre las misiones y sobre el propio diseño. A raíz de esas experiencias, en concreto cuatro, pudimos comprobar 
que el juego funcionaba bien, que era atractivo, que enganchaba y que tenía una función clara en el aprendizaje. Además, con estas experiencias pudimos seguir puliendo algunos elementos superficiales. Finalmente, durante las semanas previas a la sesión de clase dedicada a esta actividad, también realizamos funciones de comprobación de los elementos del juego. El razonamiento es que había muchos elementos incluidos que tenían base en otras aplicaciones y que el cambio de cualquier parámetro o de código fuente en la aplicación podía desajustarlos.

\section{Evaluación de la experiencia}

\subsection{Metodología de evaluación}

Para evaluar la experiencia con esta herramienta, al finalizar la actividad, realizamos una encuesta anónima a los estudiantes participantes a través de un formulario de Google. Además de incluir algunas cuestiones demográficas iniciales en la encuesta, se pidió al alumnado que reflejara, utilizando escalas tipo Likert de 7 puntos, su grado de acuerdo o desacuerdo con ciertas afirmaciones que a continuación detallamos y, finalmente, se dejó espacio para que pudiesen reflexionar sobre cuestiones positivas, negativas y de mejora del escape room digital.

Son tres las escalas que utilizamos para recabar las percepciones de los estudiantes. En la primera escala, también conocida como GAMEX (gameful experience scale) (Eppmann et al., 2018), se mide la experiencia de juego de los participantes. Es una escala multidimensional que integra la teoría de flujo en los ítems de sus dimensiones y que se enfoca específicamente en medir los estados emocionales que evocan principalmente los juegos. Sus dimensiones son:

- Diversión. Reflejaría el estado emocional positivo inherente al juego.

- Absorción. Implica pérdida de la noción del tiempo y del entorno.

- Pensamiento creativo. Un estado emocional evocado por el juego que implica activar la exploración e imaginación del participante.

- Activación. Grado de actividad que se ha conseguido durante la experiencia.

- Ausencia de afecto negativo. Sensaciones agradables y placenteras con el juego.

- Dominio. Sentimientos sobre tener el control de la situación.

La segunda se compone de tres ítems, adaptado de López-Pernas et al. (2019), a través de los cuales medimos la actitud general de los participantes hacia la actividad y, por tanto, su satisfacción y deseo de volver a participar. Por último, también incluimos una me- 
dida para evaluar en qué grado la actividad ha fomentado el aprendizaje del participante en relación con el contenido de la asignatura. Para ello adaptamos la escala utilizada por Jambhekar et al. (2020), cuya finalidad es evaluar el aprendizaje en un escape room presencial en otra rama de conocimiento.

\subsection{Resultados obtenidos}

La información obtenida para presentar los resultados en este apartado proviene de los 23 participantes de esta experiencia. Las características demográficas analizadas indican que la edad media de los participantes es de 23 años. El $78 \%$ de los participantes son mujeres y el $22 \%$ restante son hombres. En general, la muestra de participantes indica que estos hacen un uso poco habitual de juegos digitales en su tiempo libre (media de 3,34 sobre 7) y que tienen una experiencia media-baja con el escape room (3 sobre 7).

En primer lugar, respecto a la escala GAMEX, y, por tanto, en la experiencia de juego, obtenemos los resultados que se reflejan en el cuadro 4. De media se obtiene una experiencia de juego por encima del valor $5(M=5,65 ; D T=1,25)$, considerando que el juego cumple con las cualidades que debería presentar para evocar estados de flujo. Entre sus dimensiones se destacan principalmente la diversión que provoca en los participantes $(M=6,42 ; D T=0,73)$ y el pensamiento creativo $(M=5,9 ; D T=1,15)$. Con una media inferior, podíamos destacar, primero, el hecho de que puede provocar ciertos efectos negativos, al menos en algunos participantes $(M=5,3 ; D T=1,73)$, aunque en general está dentro de valores positivos y de calidad (5-7), pero nos indica espacio de mejora. Lo mismo podemos advertir de la dimensión de dominio $(M=5,3 ; D T=1,11)$, lo cual puede indicarnos que hay que ajustar el nivel de dificultad en alguna misión.

Cuadro 4. Experiencia de juego de los participantes

\begin{tabular}{|l|c|c|c|c|}
\multicolumn{1}{c|}{ Dimensiones e ítems } & Media & Mediana & DT & $\%>=5$ \\
\hline Disfrute (puntuación de la dimensión) & 6,42 & 7 & 0,73 & $99,20 \%$ \\
1. Ha sido divertido jugar. & 6,55 & 7 & 0,59 & $100 \%$ \\
2. Me ha gustado jugar. & 6,55 & 7 & 0,66 & $100 \%$ \\
3. He disfrutado mucho jugando. & 6,27 & 7 & 0,86 & $100 \%$ \\
4. Mi experiencia ha sido placentera. & 6,27 & 6 & 0,86 & $96 \%$ \\
5. Creo que el escape room es muy entretenido. & 6,45 & 7 & 0,66 & $100 \%$ \\
Absorción (puntuación de la dimensión) & 5,45 & 5 & 1,24 & $82 \%$ \\
6. Jugar me hizo olvidar dónde estaba. & 5,82 & 6 & 1,15 & $87 \%$
\end{tabular}




\section{Dimensiones e ítems}

Media

Mediana

DT

$\%>=5$

7. Me olvidé de mi entorno inmediato mientras estaba jugando.

5,82

6

1,11

$91 \%$

8. Después de jugar me sentí como de vuelta «al mundo real» después de un viaje.

5,27

5

1,12

$79 \%$

9. Jugar me alejó de todo.

5,14

5

1,14

$74 \%$

10. Mientras jugaba era completamente ajeno/a todos los que me rodeaban.

$\begin{array}{llll}5,23 & 5 & 1,20 & 79 \%\end{array}$

Pensamiento creativo (puntuación de la dimensión)

5,90

6

1,15

$91,50 \%$

11. Jugar despertó mi imaginación.

$\begin{array}{llll}5,82 & 6 & 1,23 & 87 \%\end{array}$

12. Me sentí creativo mientras jugaba.

5,91

6

1,04

$91 \%$

13. Mientras jugaba sentí que podía explorar cosas.

5,95

6

1,14

$87 \%$

14. Me sentí aventurero/a mientras jugaba.

5,95

6

1,10

$91 \%$

\section{Activación (puntuación de la dimensión)}

15. Me sentí activo/a mientras jugaba.

\section{5,50}

6

1,26

$80 \%$

16. Me sentí inquieto/a mientras jugaba.

6,23

6

0,95

$97 \%$

17. Mientras jugaba me sentí frenético/a.

5

1,34

$79 \%$

18. Mientras jugaba me sentí emocionado/a.

5

1,27

$65 \%$

5,64

6

1,12

$79 \%$

\section{Ausencia de efectos negativos}

5,30

6

1,73

$80 \%$

19. Mientras jugaba no me sentí molesto/a.

5,32

6

5,45

20. Mientras jugaba no me sentí hostil.

5,14

21. Mientras jugaba no me sentí frustrado.

\section{Dominio}

5,30

5,27

6

1,90

$79 \%$

22. Mientras jugaba tuve la sensación de estar al mando.

5,23

5

1,67

$82 \%$

3. Mientras jugaba me sentí influyente.

5,32

$+5$

1,68

$79 \%$

24. Mientras jugaba me sentí autónomo.

5,50

5

1,11

$70 \%$

25. Mientras jugaba me sentí confiado

\section{Puntuaciones medias totales}

\section{5,65}

5

1,05

$70 \%$

Nota: DT (desviación típica). 
En segundo lugar, como se refleja en el cuadro 5, las actitudes que los estudiantes reflejan tras su experiencia con las actividades son totalmente positivas.

Con valores superiores a 6 , los estudiantes recomiendan el uso de esta actividad a otros estudiantes $(M=6,55 ; D T=0,66)$ y su inclusión en otros cursos o asignaturas $(M=6,55 ; D T=0,66)$; en general, se muestran muy satisfechos de su participación $(M=6,32$; $D T=0,97)$.

Cuadro 5. Actitudes de los participantes con la actividad

\begin{tabular}{l|c|c|c|c}
\multicolumn{1}{c|}{ Actitudes hacia la actividad } & Media & Mediana & DT & $\%<5-7$ \\
\hline $\begin{array}{l}\text { 1. Recomendaría a otros estudiantes participar en } \\
\text { la actividad. }\end{array}$ & 6,55 & 7 & 0,66 & $100 \%$ \\
$\begin{array}{l}\text { 2. Me gustaría (o me hubiera gustado) que otros } \\
\text { cursos incluyeran actividades como esta. }\end{array}$ & 6,55 & 7 & 0,66 & $100 \%$ \\
\hline 3. En general, estoy satisfecho/a con la actividad. & 6,32 & 7 & 0,97 & $96 \%$ \\
\hline Puntuación media & 6,47 & 7 & 0,77 & $98,70 \%$ \\
\hline Nota: $D T$ (desviación típica). & & & & \\
\hline
\end{tabular}

En relación con los resultados de aprendizaje, el cuadro 6 muestra valores medios cercanos al $6(M=5,84 ; D T=0,98)$, por lo que podemos concluir que esta actividad se percibe como útil en el aprendizaje de la asignatura.

De forma más específica, podemos señalar algunos aspectos que son mejor valorados que otros. En concreto, los ítems $2(M=6,05 ; D T=0,92)$ y $6(M=6,27 ; D T=0,91)$, que hacen mención a la utilidad de esta herramienta como método de repaso, retención y puesta en práctica de conocimientos previos.

También se muestran valores medios altos en la utilidad de la herramienta para incrementar el conocimiento del estudiante en esta materia $(M=5,82 ; D T=0,83)$, localizar puntos débiles $(M=5,86 ; D T=0,96)$ y trabajarlos en un ámbito de simulación real $(M=5,82 ; D T=1,02)$.

Sin embargo, no parece que la actividad haya despertado tanto el interés por leer más sobre gestión de la calidad $(M=5,18 ; D T=0,98)$. 
Cuadro 6. Resultados de aprendizaje

\section{Actitudes hacia la actividad}

Media

5,82

ral en gestión de calidad.
Mediana

6

6,05

5,86

5. Esta actividad despertó mi interés por leer más sobre gestión de calidad.

6. El escape room ha sido una forma efectiva de repasar temario sobre gestión de calidad.
6

0,92

0,96

$91 \%$
2. Este formato me ayudó a retener información
en gestión de calidad.
3. Este formato me ayudó a identificar deficiencias

en mi conocimiento sobre gestión de calidad.
5,82
6
1,02
$87 \%$
misiones era similar a la información que necesito trabajar en el ámbito real de gestión de calidad.
4. La información que necesitaba para resolver las

5

$0,98 \quad 74 \%$

5,18

6,27

5,84
$\%<5-7$

$96 \%$ repasar temario sobre gestión de calidad.

Puntuación media

5,84

Nota: DT (desviación típica).

Fuente: elaboración propia.

Finalmente, la información cualitativa de las preguntas de carácter abierto del cuestionario nos permite contrastar la información que hemos obtenido de las anteriores cuestiones, así como extraer conclusiones sobre estados emocionales evocados, competencias trabajadas y sugerencias de mejora de la herramienta.

Sin duda, uno de los aspectos que mayoritariamente han señalado los estudiantes a través de sus reflexiones es la utilidad de esta actividad para la adquisición y retención de conocimientos, reforzando los resultados del cuadro 6. En la mayor parte de estas reflexiones se destaca el carácter ameno, divertido, novedoso e incluso superior a otras formas de aprendizaje tradicional. Algunos ejemplos son los siguientes:

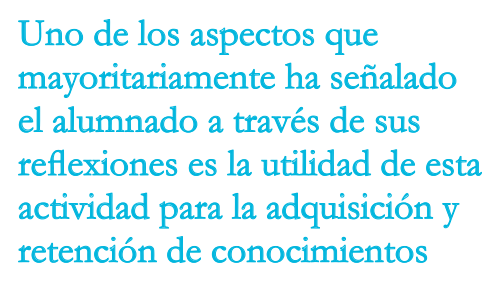

Uno de los aspectos que mayoritariamente ha señalado el alumnado a través de sus reflexiones es la utilidad de esta actividad para la adquisición y retención de conocimientos

- Participante 7. «Es una manera diferente que ayuda a clarificar los conceptos que hemos venido estudiando; además, es una actividad novedosa y entretenida». 
- Participante 14. «Es una forma de aprendizaje mucho más divertida que la tradicional y se aprende considerablemente más que en una clase tradicional».

- Participante 20. «La sensación que tengo tras realizar la actividad es que, al ser un método interactivo, he aprendido más que cuando estudio a través de la lectura».

- Participante 2. «Ha sido una muy buena manera de repasar conceptos, además de entretener y tener a toda la clase atenta».

Por otro lado, podemos señalar que esta actividad provoca estados emocionales positivos y vinculados con estados de flujo, tal y como hemos comprobado en los cuadros 4 y 5.

A través de la información cualitativa, encontramos referencia a emociones, como sensaciones agradables, de diversión, entretenimiento, dinamismo, participación o activación. Además, la gran mayoría de participantes recomiendan el juego a otros estudiantes y muestran estar satisfechos con su experiencia. Estos resultados nos sugieren que el diseño del juego ha sido óptimo. Algunos ejemplos son los siguientes:

- Participante 3. «Este juego hace que la clase sea más dinámica. Es una manera diferente de que se nos queden conceptos».

- Participante 12. «Ha sido muy divertido y una forma entretenida de repasar el temario y ponerlo en práctica con supuestos "reales"».

- Participante 1. «Ha sido un momento agradable y una manera de aprender muy amena».

- Participante 9. «Con este juego he sentido emoción a la hora de averiguar las pruebas y también satisfacción cuando lograba respondarlas correctamente».

- Participante 17. «Ha sido una actividad divertida y activa, donde he podido aprender de una forma diferente sobre la asignatura».

En relación con las posibles competencias transversales que se trabajan en el juego, podemos señalar que algunos participantes piensan que la actividad promueve especialmente el trabajo en equipo y la cooperación grupal, competencia transversal que indicamos previamente como objetivo clave en el desarrollo de esta actividad. Algunos ejemplos son los siguientes:

- Participante 13. «El hecho de realizar una actividad tan dinámica y participativa nos motiva a repasar el temario y poner en práctica la teoría de la asignatura. Me parece que es una forma muy divertida de aprender y de trabajar de forma grupal, y con la que mejorar nuestra imaginación y la comunicación entre los miembros del equipo». 
- Participante 19. «Destacaría como punto positivo de la actividad el hecho de tener que trabajar de forma cooperativa con el resto de miembros del equipo».

Algunos de los participantes dejaron constancia de varios aspectos que no consideraron positivos y que sería conveniente revisar en futuras aplicaciones. En especial, los participantes destacaron dos cuestiones. La primera cuestión, y la más importante, es el carácter competitivo de la actividad, que puede reducir la sensación de placer (evocando algunos sentimientos como impaciencia, frustración, agobio, etc.), ya que los participantes se centran más en terminar la actividad antes que el resto que en disfrutar de la exploración del escenario y de la resolución de las misiones. Algunos ejemplos son los siguientes:

- Participante 14. «No considero que exista ningún aspecto negativo, pero, si tuviera que comentar algo, sería que el juego incrementa la competitividad entre alumnos y eso puede frustrar».

- Participante 10. «Estaba impaciente por acabar de los primeros».

- Participante 23. «En algunos casos me he sentido frustrada en relación con los otros grupos, ya que algunos retos no los hemos acertado a la primera».

La segunda cuestión, que desde nuestro punto de vista tiene relación con la primera, es que bloquearse en algunas misiones puede generar también estados de frustración o de agobio. Este bloqueo, bajo nuestro criterio, viene dado en algunos casos por el carácter competitivo o la presión temporal, hecho que en algún grupo condujo a que se dejasen de explorar algunos elementos del escenario y que directamente tratasen de solventar la misión sin reflexionar. No obstante, una de las competencias que se pretendía trabajar era la gestión del estrés, el rendimiento bajo presión y la tolerancia con la frustración y la adversidad. Por tanto, esta situación la abordamos con detalle en el siguiente apartado, donde reflexionaremos sobre las lecciones aprendidas. Algunos ejemplos son los siguientes:

- Participante 9. «Nos hemos frustrado un poco en la segunda misión».

- Participante 2. «Sentía frustración cuando no acertaba algo».

- Participante 16. «He sentido frustración por no conseguir completar las pruebas más rápidamente».

En cuanto a las principales sugerencias, la mayoría de los participantes considera que la actividad no necesita ninguna mejora, que no hay inconvenientes, y, por tanto, las sugerencias van encaminadas a la integración de este tipo de actividad en otras sesiones y asignaturas. No obstante, algunos participantes sí que han señalado ciertas sugerencias, aunque no existe una concordancia u homogeneidad entre las mismas. Podemos destacar, quizá, que algunos solicitan la inclusión de más niveles, misiones y objetos que puedan ser investigados. Algunos participantes eliminarían las puntuaciones competitivas 
y, finalmente, otros apuntan a detalles técnicos para mejorar distintas funciones del juego. Algunos ejemplos son los siguientes:

- Participante 6. «Ha sido una actividad muy divertida y eficiente para la asignatura. Propondría realizar más actividades de este tipo».

- Participante 13. «Lo integraría en más asignaturas».

- Participante 1. «Pondría incluir más escenarios u objetos para investigar».

- Participante 7. «Me gustaría que hubiera más objetos para investigar o nuevos retos".

- Participante 5. «Propongo que el diagrama de pescado pueda ser completado con una función de arrastre, ya que, de la otra manera, estresa demasiado».

- Participante 16. «Que el móvil en el que hay que poner los números funcione mejor».

\section{Lecciones aprendidas}

En este apartado vamos a presentar las principales lecciones que hemos aprendido con nuestra experiencia en el diseño y aplicación de un escape room digital, las cuales consideramos valiosas para la comunidad docente por dos motivos. En primer lugar, por la escasez de experiencias docentes universitarias con el uso de escapes rooms digitales. Y, en segundo lugar, porque en el área de conocimiento de la organización de empresas, la evidencia es todavía menor. Por tanto, las reflexiones que a continuación aportamos constituyen una fuente de valor para aquellos docentes, especialmente universitarios, que tengan interés en el diseño de herramientas de aprendizaje basadas en el juego digital.

La primera lección que destacamos con nuestra experiencia es la importancia que tiene determinar cuál es el elemento de presión que se introduce en el escape room digital. Basándonos en la información transmitida por los estudiantes, el elemento competitivo no es el más idóneo. Es cierto que hay estudiantes con perfiles más competitivos que otros, pero, en general, concluimos que este elemento, a pesar de las buenas valoraciones obtenidas sobre la herramienta y la satisfacción del alumnado, ha restado cierta calidad en la experiencia, generando actitudes en algunos estudiantes que debemos evitar. Por tanto, en futuras aplicaciones consideramos importante introducir como elemento de presión un periodo temporal
La primera lección que destacamos con nuestra experiencia es la importancia que tiene determinar cuál es el elemento de presión que se introduce en el escape room digital. Basándonos en la información transmitida por el alumnado, el elemento competitivo no es el más idóneo 
específico. Con este elemento se evita la competitividad entre grupos y se potencia el hecho de que los alumnos no tengan reparos en explorar todo el mapa y en reflexionar con una cierta calma (sin perder de vista el tiempo restante) los objetivos planteados para la resolución de la misión.

Basándonos en los resultados de satisfacción, en la experiencia con el juego, en el aprendizaje y en la información cualitativa expuesta por los participantes, sin duda, recomendamos la inclusión de este tipo de juegos en la planificación docente universitaria. Hemos podido comprobar de primera mano cómo el estudiantado estaba completamente concentrado en la experiencia, coordinándose y cooperando activamente por un propósito común, mostrando fuertes estados emocionales, como alegría, satisfacción y cierto júbilo cuando conseguían superar un reto o encontrar una pista, y frustración, estrés o agobio cuando no lograban su propósito en un primer intento.

En relación con estas últimas emociones (frustración, estrés o agobio), por sí mismas no las consideramos negativas si en el propósito docente se pretende trabajar la gestión emocional y la resolución de problemas, ya que el alumnado debe tener la entereza de, ante una adversidad profesional, intentar dar con la solución de nuevo y tratar de pensar qué es lo que está fallando. No obstante, con esta experiencia podemos señalar que estas emociones, para tener un impacto positivo en los objetivos planteados, deben ser puntuales y no representar la emoción característica de toda la experiencia de juego. Si esto ocurre es porque hay un fallo en el planteamiento que puede inducir al error o porque las destrezas son muy inferiores a la dificultad del problema que se quiere resolver.

Otra lección aprendida que se encuentra vinculada con el diseño de la actividad es la importancia de la etapa de revisión de errores. A pesar de realizar alrededor de 15 revisiones desde la finalización del primer boceto, dada la profundidad del juego y la multitud de interconexión entre elementos y aplicaciones externas en funcionamiento, siempre encontrábamos algún fallo o cuestión que se podía mejorar.

En algunos casos, los errores eran cuestiones del equipo diseñador, en otros, eran cuestiones asociadas a las herramientas. Por tanto, hay una relación directa entre la profundidad y complejidad del juego y esta fase de revisión que debe extenderse hasta prácticamente el día previo a la realización de la actividad. En nuestro caso, a través de la experiencia del estudiantado también pudimos comprobar que algunos elementos pueden ser mejorados, como la velocidad de introducción de números en el móvil o cambiar la función de escribir las causas en huecos en blanco por alguna funcionalidad de arrastre.

Por otro lado, tras esta experiencia, consideramos que el aprendizaje basado en juegos digitales tiene un potencial tremendo de cara al futuro y que estamos en una etapa muy prematura y de mera exploración. El incremento de herramientas de diseño de juegos, 
como Unreal Engine o Unity, a través de las cuales es posible realizar un juego sin introducir líneas de código, con plantillas y funciones muy intuitivas, nos abre, como docentes, la puerta a una nueva dimensión. Actualmente, es posible diseñar espacios realistas (en 3D) y en mundo abierto, donde al participante se le puede exigir completar tareas específicas de simulación real.
Entre los aspectos positivos de esta experiencia, destaca que es una actividad que «engancha» a toda la clase y que contribuye al aprendizaje del participante de manera amena y divertida

A través de la realidad virtual, los alumnos pueden situarse en multitud de actividades de simulación, como, por ejemplo, simular el proceso de selección de una serie de candidatos, donde los alumnos toman el rol de un reclutador. El carácter realista de nuestra experiencia ha sido uno de los aspectos mejor valorados por el alumnado.

Finalmente, y como conclusión, destacamos algunos aspectos positivos de nuestra experiencia, pero también algunos negativos:

- Aspectos positivos:

- Es una actividad que «engancha» a toda la clase y que contribuye al aprendizaje del participante de manera amena y divertida.

- Es reutilizable, modificable y ampliable para ser utilizada en posteriores cursos o en varios grados o másteres de la misma temática.

- Es una actividad totalmente innovadora y creativa que influye positivamente en el modo en que el estudiantado percibe la asignatura y en la forma de implicación del profesorado.

- Supone un reto creativo para el equipo docente que, cuando concluye con éxito, produce una sensación de satisfacción.

- Aspectos negativos:

- El incremento considerable de la carga de trabajo, aunque depende de la profundidad del juego (en nuestro caso, 250 horas de trabajo con dominio previo de esta herramienta).

- Puede implicar cierto desembolso económico, dependiendo de las funcionalidades que quieras incluir desde la herramienta.

- El juego puede quedar obsoleto si la herramienta a través de la cual se diseña integra funcionalidades o cambios en su código que repercuten en algunas acciones, por lo que exige cierto mantenimiento del mismo. 


\section{Referencias bibliográficas}

Admiraal, W., Huizenga, J., Akkerman, S. y Ten Dam, G. (2011). The concept of flow in collaborative game-based learning. Computers in Human Behavior, 27(3), 1.1851.194.

Álvarez López, J. A. y Sampablo Buezas, R. (septiembre-diciembre 2020). Una propuesta de modelo educativo para las organizaciones exponenciales. Tecnología, Ciencia y Educación, 17, 149-179. https://doi.org/ 10.51302/tce.2020.493

Bejarano, A. F., Correa, J. D. y Figueroa, P. (2020). Escape room virtual reality: a tool for diagnosis and treatment of attention deficit disorder. 22nd Symposium on Virtual and Augmented Reality (SVR) (pp. 331-338). IEEE.

Csikszentmihalyi, M. (1978). Intrinsic rewards and emergent motivation. En M. R. Lepper y D. Greene (Eds.). The Hidden Costs of Reward: New Perspectives on the Psychology of Human Motivation (pp. 205-216). Wiley.

Csikszentmihalyi, M. (1990). Flow: The Psychology of Optimal Experience. HarperPerennial.

Deterding, S., Dixon, D., Khaled, R. y Nacke, L. (2011). From game design elements to gamefulness: defining gamification. Proceedings of the 15th International Academic MindTrek Conference: Envisioning Future Media Environments (pp. 9-15). ACM.

Elsherbiny, M. M. K. y Al Maamari, R. H. (2021). Game-based learning through mobile phone apps: effectively enhancing learning for social work students. Social Work Education, 40(3), 315-332.

Eppmann, R., Bekk, M. y Klein, K. (2018). Gameful experience in gamification: construction and validation of a gameful expe- rience scale [GAMEX]. Journal of Interactive Marketing, 43, 98-115.

European Commission/EACEA/Eurydice. (2020). The European Higher Education Area in 2020. Bologna Process Implementation Report. Publication Office of the European Union.

Garris, R., Ahlers, R. y Driskell, J. E. (2002). Games, motivation, and learning: a research and practice model. Simulation and Gaming, 33, 441-467.

Gómez, M. (2020). A COVID-19 intervention: using digital escape rooms to provide professional development to alternative certification educators. Journal of Technology and Teacher Education, 28(2), 425-432.

González-Marcos, A., Navaridas-Nalda, F., Jiménez-Trens, M. A., Alba-Elías, F. y Ordieres-Meré, J. (2021). Efectos académicos de una enseñanza mixta versus metodología única centrada en el profesor y enfoques de aprendizaje. Revista de Educación, 392, 123-154.

Hung, C. Y., Sun, J. C. Y. y Yu, P. T. (2015). The benefits of a challenge: student motivation and flow experience in tablet-PCgame-based learning. Interactive Learning Environments, 23(2), 172-190.

livari, N., Sharma, S. y Ventä-Olkkonen, L. (2020). Digital transformation of everyday life-How COVID-19 pandemic transformed the basic education of the young generation and why information management research should care? International Journal of Information Management, 55. https:// doi.org/10.1016/j.ijinfomgt.2020.102183

Jambhekar, K., Pahls, R. P. y Deloney, L. A. (2020). Benefits of an escape room as a novel educational activity for radiology residents. Academic Radiology, 27(2), 276-283. 
Jiménez, C., Arís, N., Magreñán-Ruiz, Á. A. y Orcos, L. (2020). Digital escape room, using Genial.ly and a breakout to learn algebra at secondary education level in Spain. Education Sciences, 10(10), 271.

Kapp, K. M. (2012). The Gamification of Learning and Instruction: Game-Based Methods and Strategies for Training and Education. John Wiley \& Sons.

Liu, C. C., Cheng, Y. B. y Huang, C. W. (2011). The effect of simulation games on the learning of computational problem solving. Computers and Education, 57(3), 1.907-1.918.

López-Pernas, S., Gordillo, A., Barra, E. y Quemada, J. (2019). Examining the use of an educational escape room for teaching programming in a higher education setting. IEEE Access, 7, 31.723-31.737.

López-Pernas, S., Gordillo, A., Marín, A. y Barra, E. (2020). Guía metodológica para el diseño y ejecución de escape rooms educativas mediante la plataforma escapp. Colección Digital Politécnica (Universidad Politécnica de Madrid).

Nakamura, J. y Csikszentmihalyi, M. (2002). The concept of flow. En C. R. Snyder y S. J. Lopez (Eds.), Handbook of Positive Psychology (pp. 89-105). Oxford University Press.

Nicholson, S. (2015). A Recipe for Meaningful Gamification. Gamification in Education and Business. Springer.

Perrotta, C., Featherstone, G., Aston, H. y Houghton, E. (2013). Game-Based Learning: Latest Evidence and Future Directions
(NFER Research Programme: Innovation in Education). NFER.

Prensky, M. (2001). Digital natives, digital immigrants part II: Do they really think differently? On the Horizon, 9(6), 1-9.

Sempere Pla, S. (mayo-agosto 2020). Proyecto de gamificación basado en el escape room aplicado a un aula bilingüe de educación primaria con enfoque AICLE. Tecnología, Ciencia y Educación, 16, 5-40. https://doi.org/10.51302/tce.2020.437

Veldkamp, A., Daemen, J., Teekens, S., Koelewijn, S., Knippels, M. C. P. y Joolingen, W. R. van. (2020). Escape boxes: bringing escape room experience into the classroom. British Journal of Educational Technology, 51(4), 1.220-1.239.

Vergne, M. J., Smith, J. D. y Bowen, R. S. (2020). Escape the (remote) classroom: an online escape room for remote learning. Journal of Chemical Education, 97(9), 2.845-2.848.

Villar Lama, A. (2018). Ocio y turismo millennial: el fenómeno de las salas de escape. Cuadernos de Turismo, 41, 615-636.

Wiemker, M., Elumir, E. y Clare, A. (2015). Escape room games: can you transform an unpleasant situation into a pleasant one? White Paper.

Wu, C., Wagenschutz, H. y Hein, J. (2018). Promoting leadership and teamwork development through escape rooms. Medical Education, 52(5), 561-562.

Zichermann, G. y Cunningham, C. (2011). Gamification by Design. O'Reilly. 